\title{
SKI activates the Hippo pathway via LIMD1 to inhibit cardiac fibroblast activation
}

\author{
Natalie M. Landry 1,2,4 Sunil G. Rattan ${ }^{1,2,4} \cdot$ Krista L. Filomeno $^{1,2,4} \cdot$ Thomas W. Meier $^{1,4} \cdot$ Simon C. Meier ${ }^{1,4}$. \\ Sarah J. Foran ${ }^{1} \cdot$ Claire F. Meier $^{1} \cdot$ Navid Koleini $^{1,2,4} \cdot$ Robert R. Fandrich $^{1}$ • Elissavet Kardami ${ }^{1,3,4} \cdot$ Todd A. Duhamel $^{1,5}$. \\ Ian M. C. Dixon ${ }^{1,2,4}$ (1)
}

Received: 28 April 2020 / Accepted: 24 March 2021 / Published online: 13 April 2021

(c) The Author(s) 2021

\begin{abstract}
We have previously shown that overexpression of SKI, an endogenous TGF- $\beta_{1}$ repressor, deactivates the pro-fibrotic myofibroblast phenotype in the heart. We now show that SKI also functions independently of SMAD/TGF- $\beta$ signaling, by activating the Hippo tumor-suppressor pathway and inhibiting the Transcriptional co-Activator with PDZ-binding motif (TAZ or WWTR1). The mechanism(s) by which SKI targets TAZ to inhibit cardiac fibroblast activation and fibrogenesis remain undefined. A rat model of post-myocardial infarction was used to examine the expression of TAZ during acute fibrogenesis and chronic heart failure. Results were then corroborated with primary rat cardiac fibroblast cell culture performed both on plastic and on inert elastic substrates, along with the use of siRNA and adenoviral expression vectors for active forms of SKI, YAP, and TAZ. Gene expression was examined by qPCR and luciferase assays, while protein expression was examined by immunoblotting and fluorescence microscopy. Cell phenotype was further assessed by functional assays. Finally, to elucidate SKI's effects on Hippo signaling, the SKI and TAZ interactomes were captured in human cardiac fibroblasts using BioID2 and mass spectrometry. Potential interactors were investigated in vitro to reveal novel mechanisms of action for SKI. In vitro assays on elastic substrates revealed the ability of TAZ to overcome environmental stimuli and induce the activation of hypersynthetic cardiac myofibroblasts. Further cell-based assays demonstrated that SKI causes specific proteasomal degradation of TAZ, but not YAP, and shifts actin cytoskeleton dynamics to inhibit myofibroblast activation. These findings were supported by identifying the bi-phasic expression of TAZ in vivo during post-MI remodeling and fibrosis. BioID2-based interactomics in human cardiac fibroblasts suggest that SKI interacts with actin-modifying proteins and with LIM Domaincontaining protein 1 (LIMD1), a negative regulator of Hippo signaling. Furthermore, we found that LATS2 interacts with TAZ, whereas LATS1 does not, and that LATS2 knockdown prevented TAZ downregulation with SKI overexpression. Our findings indicate that SKI's capacity to regulate cardiac fibroblast activation is mediated, in part, by Hippo signaling. We postulate that the interaction between SKI and TAZ in cardiac fibroblasts is arbitrated by LIMD1, an important intermediary in focal adhesion-associated signaling pathways. This study contributes to the understanding of the unique physiology of cardiac fibroblasts, and of the relationship between SKI expression and cell phenotype.
\end{abstract}

Keywords Fibroblast $\cdot$ Cardiac fibrosis $\cdot$ Extracellular matrix $\cdot$ Hippo signaling $\cdot$ SKI $\cdot$ TAZ

\section{Abbreviations}

aSMA Alpha-Smooth Muscle Actin

AP-1 Activator Protein-1

Ian M. C. Dixon

idixon@sbrc.ca

1 Institute of Cardiovascular Sciences, St. Boniface Hospital Albrechtsen Research Centre, 351 Taché Avenue, Winnipeg, MB, Canada

2 Department of Physiology and Pathophysiology, University of Manitoba, Winnipeg, Canada
$\beta$-TrCP1 Beta-Transducin repeat Containing Protein 1

CARMIL2 Capping Protein Regulator and Myosin 1 Linker 2
3 Department of Human Anatomy and Cell Science, University of Manitoba, Winnipeg, Canada

4 Rady Faculty of Health Sciences, Max Rady College of Medicine, University of Manitoba, Winnipeg, Canada

5 Faculty of Kinesiology and Recreation Management, University of Manitoba, Winnipeg, Canada 


\begin{tabular}{|c|c|}
\hline CK1 & Casein Kinase 1 \\
\hline CTGF & Connective Tissue Growth Factor \\
\hline CTHRC1 & Collagen Triple Helix Repeat Containing 1 \\
\hline CYR61 & $\begin{array}{l}\text { Cysteine-Rich angiogenic inducer } 61 \text { (also } \\
\text { called CCN1) }\end{array}$ \\
\hline ECM & Extracellular Matrix \\
\hline ED-A & Extracellular Domain-A \\
\hline LATS $1 / 2$ & Large Tumor Suppressor 1 or 2 \\
\hline LIMD1 & LIM Domain-containing protein 1 \\
\hline MST1/2 & Macrophage-Stimulating 1 or 2 \\
\hline NCoR1 & Nuclear Co-Repressor 1 \\
\hline POSTN & Periostin \\
\hline RLTPR & $\begin{array}{l}\text { RGD, Leucine-Rich Repeat, Tropomodulin } \\
\text { And Proline-Rich-Containing Protein }\end{array}$ \\
\hline SMAD & Mothers Against Decapentaplegic homolog \\
\hline TAZ & $\begin{array}{l}\text { Transcriptional co-Activator with PDZ-bind- } \\
\text { ing motif (also called WWTR1) }\end{array}$ \\
\hline TEAD & TEA Domain family member \\
\hline TEF & Transcriptional Enhancer Factor \\
\hline WASHC5 & WASH Complex Subunit 5 \\
\hline WWTR1 & $\begin{array}{l}\text { WW domain-containing Transcription Regu- } \\
\text { lator protein } 1 \text { (also called TAZ) }\end{array}$ \\
\hline YAP & Yes-Associated Protein \\
\hline
\end{tabular}

\section{Background}

Following soft-tissue injury, rapid expansion and remodeling of the extracellular matrix (ECM) is essential for local wound healing response. However, chronic activation of fibroblasts into the hyper-secretory myofibroblast phenotype leads to excess synthesis and deposition of matrix and matrix-associated proteins, including fibrillar collagens types I and III [18, 27], periostin [4, 46], and the cellassociated fibronectin extracellular domain A (ED-A FN) splice variant [29, 45]. Another hallmark of the myofibroblast phenotype is the incorporation of alpha-smooth muscle actin $(\alpha \mathrm{SMA})$ into cytoskeletal actin stress fibers [50], a trait which imparts a contractile quality to the cell. In the heart, post-myocardial infarction (post-MI) wound healing progresses into chronic expansion of the infarct scar, as the heart possesses limited innate regenerative properties. Ensuing myocardial fibrosis and subsequent loss of functional myocardium then contributes to the patient's decline into heart failure [30]. Despite this reality, there are no effective therapeutic interventions to prevent or heal cardiac fibrosis.

Originally identified as the cellular homolog of the avian Sloan-Kettering virus, SKI is a multi-functional transcriptional co-regulator, commonly regarded as a negative regulator of SMAD-dependent TGF- $\beta$ signaling $[7,59]$. In the nucleus, the SKI associates with Nuclear Co-Repressors (NCoR) and HDAC proteins to form an inhibitory complex
$[52,54]$, believed to confer anti-fibrotic properties. SKI dysfunction is causal to Shprintzen-Goldberg syndrome, a connective tissue disorder similar to Marfan syndrome, which manifests from a loss-of-function mutation in SKI's SMADbinding domain [42]. In addition, there is some evidence that SKI also functions in an SMAD-independent manner, specifically via the inhibition of CREB-binding protein (CBP) and the AP-1 complex $[10,61]$. Our group has previously reported that ectopic expression of SKI in primary cardiac myofibroblasts reduced the expression of fibrillar collagens and $\alpha$ SMA, which was observed in concert with a decrease in cellular contractility $[11,12]$. Furthermore, SKI is dysregulated and sequestered to the cytoplasm in a post-MI model of cardiac remodeling, suggesting that it contributes to fibroblast phenotype regulation [12]. We found that SKI also modulates MMP-9 expression and releases from primary cardiac fibroblasts, indicating that it may also influence the deposition and removal of ECM during post-MI wound healing [31]. As SKI's effects in cardiac fibroblasts are substantial and robust, it is possible that its functions within the cell extend beyond SMAD inhibition.

As a potential contributor to the regulation of the cardiac fibroblast phenotype, the Hippo signaling pathway was identified as another potential mechanism by which SKI moderates the activation of myofibroblasts. The Hippo pathway is a tumor-suppressor signaling cascade that is composed of core kinases including Macrophage Stimulating 1 or 2 (Mst1/2) and Large Tumor Suppressor 1 or 2 (LATS1/2) [19, 63]. These kinases, along with several scaffolding proteins, regulate the primary nuclear effectors of the pathway, YesAssociated Protein (YAP) [9] and its paralog, Transcriptional co-Activator with PDZ-binding motif (TAZ, also called WWTR1) [25]. Both YAP and TAZ do not possess any direct DNA-binding domains; however, they strongly associate with TEAD and TEF transcription factors [24, 62] to promote the expression of pro-fibrotic targets such as Connective Tissue Growth Factor (CTGF) and CysteineRich angiogenic factor 61 (CYR61) [8]. When activated, the core Hippo signaling complex inhibits YAP and TAZ by phosphorylation via LATS1/2, followed by cytoplasmic shuttling and proteasomal degradation. In the heart, it has been determined that Hippo signaling plays an important role in cardiac development and homeostasis [22, 57], and considerable effort to investigate its promotion of cardiomyocyte re-entry into the cell cycle for post-MI regeneration. While YAP/TAZ signaling is linked to the pathogenesis of various fibro-proliferative diseases [3, 39, 49], there is limited information regarding the role of Hippo and YAP/ TAZ signaling in cardiac fibroblast phenotype regulation in the injured heart.

Herein, we present evidence that SKI activates the Hipposignaling pathway, and specifically does so to inhibit the pro-fibrotic activity of TAZ, independent of YAP. Our study 
suggests that SKI dysregulation during post-MI remodeling results in the inhibition of the Hippo kinase cascade, thus allowing fibrosis to persist in the myocardium.

\section{Materials and methods}

\section{Ethics}

All studies presented herein were conducted in accordance with the guidelines and principles of the Canadian Council on Animal Care (CCAC), as well as the Canadian TriCouncil Policy Statement for Ethical Conduct on Research Involving Humans (TCPS 2, 2018). Ethics approval for both animal and human tissue collection was provided by the University of Manitoba's Office of Research Ethics and Compliance, and Protocol Management and Review Committee. All cardiac surgery patients at St. Boniface General Hospital signed a consent form allowing tissue materials removed and discarded as a normal part of surgery to be used for research purposes, according to the University of Manitoba and St. Boniface General Hospital institutional polices. Based on this, the Research Ethics Board of the University of Manitoba waived the need for individual informed consent by donors and granted permission for use of human tissue from cardiac surgery patients (\#H2016:274).

\section{In Vivo model of myocardial infarction}

Young male Sprague-Dawley ranging from 125 to $150 \mathrm{~g}$ in mass underwent left anterior descending (LAD) coronary artery ligation or sham surgery as previously described [14]. Animals were randomly sorted into the following timepoints for echocardiography and subsequent tissue harvest: $48 \mathrm{~h}$, 4 days, 1 week, 2 weeks, 4 weeks, and 8 weeks. A total of $n=30$ sham-operated and $n=49$ LAD-ligated animals were used to acquire the samples for this study.

Tissues were collected from animals anaesthetized with $3 \%$ isoflurane for a minimum of $10 \mathrm{~min}$. Hearts were excised and immediately washed in 1X PBS, after which they were dissected into discrete sections for future analyses. The sham-operated hearts were separated into right (RV) and left (LV) ventricles, while the LAD ligated hearts were separated into $\mathrm{RV}$, viable LV, and infarcted LV (scar). Tissues intended for histology were frozen fresh in optimal cutting temperature (OCT) compound (VWR International, Radnor, PA; \#95,057-838) and flash-freezing in a dry ice-ethanol bath. Freshly isolated tissue and frozen blocks were immediately stored at $-80{ }^{\circ} \mathrm{C}$ until used.

\section{Protein isolation from frozen tissue}

Frozen tissue samples were crushed using a pre-chilled mortar and pestle, while submerged in an excess volume of liquid nitrogen. The crushed tissue (and liquid nitrogen) was then decanted into a sterile $15 \mathrm{~mL}$ conical tube containing $1 \mathrm{~mL}$ tissue lysis buffer (125 mM Tris, pH 7.4; 1\% SDS; $5 \%$ glycerol; $1 \mathrm{X}$ protease inhibitor cocktail (Sigma-Aldrich, \#P8340), $10 \mathrm{mM} \mathrm{NaF}, 1.0 \mathrm{mM} \mathrm{Na}_{3} \mathrm{VO}_{4}$, and $1.0 \mathrm{mM}$ EGTA) per $100 \mathrm{mg}$ of tissue. The samples were then incubated on ice for $1 \mathrm{~h}$, with periodic vortexing to ensure complete lysis. Following $10 \mathrm{~s}$ of sonication, the lysate was transferred to QIAshredder columns (QIAgen, Hilden, Germany) and centrifuged according to the manufacturer's recommended conditions. The flow-through was collected and stored at $-80{ }^{\circ} \mathrm{C}$ until use.

\section{Preparation of tissue culture surfaces}

Silicone elastic tissue culture plates and coverslips bearing an elastic modulus of $5 \mathrm{kPa}$ were purchased from Excellness Biotech (Lausanne, Switzerland). Prior to use, surfaces were sterilized $100 \%$ isopropanol and thoroughly dried. Surfaces were then coated overnight at $37^{\circ} \mathrm{C}$ using an excess volume of $10 \mu \mathrm{g} / \mathrm{mL}$ porcine gelatin type A diluted in PBS, and used at a concentration of $2 \mu \mathrm{g} / \mathrm{cm}^{2}$. The following day, the gelatin solution was aspirated, and cells were plated immediately in sufficient culture medium.

\section{Primary rat cardiac fibroblast isolation and culture}

Rat primary cardiac fibroblasts were isolated, as previously described [32]. Male Sprague-Dawley rats weighing 101-125 g were anaesthetized with a ketamine-xylazine cocktail (100 mg/kg ketamine; $10 \mathrm{mg} / \mathrm{kg}$ xylazine) administered intraperitoneally. After verifying the loss of limb reflexes, heparin $(6 \mathrm{mg} / \mathrm{kg})$ was administered intravenously via the saphenous artery. Hearts were immediately excised and placed in 1:1 Dulbecco's Modified Eagle's medium/ Ham's F12 nutrient mixture (DMEM/F12, Gibco \# 11,320033). The hearts were cannulated via the aorta on a Langendorff apparatus and then subject to retrograde perfusion with DMEM/F12 for $5 \mathrm{~min}$, followed by Minimum Essential Medium, Spinner's Modification (S-MEM, Gibco \# 11,380037) for another $5 \mathrm{~min}$ to flush out calcium and promote cell dissociation. To digest the tissue, the hearts were then perfused with S-MEM supplemented with $600 \mathrm{U} / \mathrm{mL}$ collagenase type II (Worthington Biochemical Corporation, Lakewood, NJ; \#CLS-2) with recirculation for $25 \mathrm{~min}$ at $37^{\circ} \mathrm{C}$.

For quiescent fibroblast culture, the digested tissue was incubated at $37{ }^{\circ} \mathrm{C}, 5 \% \mathrm{CO}_{2}$ for $10 \mathrm{~min}$, and then neutralized with $10 \mathrm{~mL}$ of Ham's F-10 medium (F-10, Gibco, \# 
11,550-043) supplemented with $2 \%$ fetal bovine serum (FBS) and $100 \mathrm{U} / \mathrm{mL}$ penicillin-streptomycin. The tissue was further dissociated by trituration and the final cell suspension was gravimetrically passed through a $40 \mu \mathrm{m}$ sterile cell strainer (Thermo Fisher Scientific, Waltham, MA). The cells were pelleted by centrifugation at $200 \times g$ for $5 \mathrm{~min}$, and re-suspended in complete cell culture medium. Fibroblasts were allowed to adhere to prepared elastic surfaces for $3 \mathrm{~h}$ at $37{ }^{\circ} \mathrm{C}, 5 \% \mathrm{CO}_{2}$. Adherent cells were then briefly washed twice with 1X PBS supplemented with penicillin-streptomycin, and fresh complete culture medium was added. For the following 3 days, the cultures were once again washed, and the growth medium was replaced. Cells were used for experimentation 4-day post-plating.

For activated myofibroblast culture, digested tissue was incubated as described above, but was neutralized with DMEM/F12 supplemented with $10 \%$ FBS and penicillin-streptomycin. Cells were allowed the adhere for $2 \mathrm{~h}$ at $37{ }^{\circ} \mathrm{C}, 5 \% \mathrm{CO}_{2}$ on conventional plastic surfaces prior to brief washing in $1 \mathrm{X}$ PBS and replacing the complete culture medium. Cells were allowed to proliferate until 75-80\% confluence prior to passaging. Experiments using activated rat myofibroblasts were passaged once (P1).

\section{Adenoviral constructs and in vitro infection}

All adenoviral constructs were designed to overexpress the human gene product under control of the CMV promoter. The viruses overexpressing LacZ, HA-tagged SKI, and the MYC-BioID2 fusion proteins, were generated by our lab using Adeno-X Expression System (Takara Bio Inc., Kusatsu, Japan), as per the manufacturer's instructions. The FLAGtagged constitutively active YAP[5SA] and MYC-tagged TAZ[4SA] viruses were designed by our lab and generated by VectorBuilder Inc. (Chicago, IL, USA). Viral DNA vectors were sequenced for the presence of the transgene insert at The Centre for Applied Genomics (Hospital for Sick Children, Toronto, ON) prior to amplification.

To overexpress a given protein of interest, cells were serumstarved overnight $(\sim 16 \mathrm{~h})$ in F-10 medium supplemented with penicillin-streptomycin. The following day, the cells were infected with a vector-dependent multiplicity of infection (MOI) of 20-50 in serum-free F-10 medium. Viral infection was allowed to proceed for approximately $36 \mathrm{~h}$ prior to harvesting for analysis.

\section{Primary cell treatment with small molecule inhibitors}

P1 primary rat cardiac fibroblasts were seeded onto stiff plastic culture plates at about $20 \%$ confluency $\left(\sim 7.0 \times 10^{5}\right.$ cells $/ 10 \mathrm{~cm}$ dish). Once the cells reached $40-50 \%$ confluency, they were serum-starved overnight in DMEM/F12.
The culture medium was then replenished (still serum-free), and supplemented with one of the following small-molecule inhibitors: MG132 (1 $\mu$ M; Sigma-Aldrich; \#M7449), GS143 (1 $\mu \mathrm{M}$; Tocris Bioscience, Bristol, UK; \#5636), D4476 (500 nM; Selleckchem, Houston, TX; \#S7642). Control plates were treated with DMSO alone. Cells were pre-treated with the compounds for $3 \mathrm{~h}$, after which they were infected with either Ad-LacZ or Ad-HA-SKI (as described above; MOI of 50) and cells were harvested $24 \mathrm{~h}$ post-infection.

\section{siRNA-mediated gene knockdown}

First-passage (P1) cardiac myofibroblasts were seeded at $1.0 \times 10^{4}$ cells in each well of a 6 -well dish. Cells were left to adhere overnight in DMEM/F12 supplemented with $10 \%$ FBS and $100 \mathrm{U} / \mathrm{mL}$ of penicillin-streptomycin. The cells were then starved overnight in serum-free, antibiotic-free DMEM (Gibco, \# 10,564-011). The following day, cells were transfected for $24 \mathrm{~h}$ with $50 \mathrm{nM}$ of either a non-targeting siRNA pool (Dharmacon, Lafayette, CO) or a 4-oligo pool targeting the gene of interest using Lipofectamine RNAiMax (ThermoFisher) as per the manufacturer's protocol. If the assay was performed in conjunction with protein overexpression, the following day the medium was changed, and the cells were infected with the appropriate viral construct. Whole cell lysates were collected for analysis after approximately $36 \mathrm{~h}$ of viral overexpression.

\section{Protein isolation from cell cultures}

Fibroblasts cultured on elastic surfaces were trypsinized and pelleted prior to lysis. Cell pellets were lysed with RIPA lysis buffer (1\% NP-40; 0.5\% NaDOC; 0.1\% SDS; $50 \mathrm{mM}$ Tris- $\mathrm{HCl}$, pH 7.4; $150 \mathrm{mM} \mathrm{NaCl} ; 10 \%$ glycerol; $1 \mathrm{mM}$ EDTA) supplemented with protease inhibitors (Sigma, P8430) and phosphatase inhibitors (10 mM NaF; $1 \mathrm{mM} \mathrm{Na} 3 \mathrm{VO}_{4} ; 1 \mathrm{mM}$ EGTA). Lysates were incubated on ice for 30 min with periodic vortexing; this was followed by brief sonication and centrifugation at $16000 \times g$ for $15 \mathrm{~min}$ at $4{ }^{\circ} \mathrm{C}$. Cleared lysates were then transferred to fresh microcentrifuge tubes for total protein determination by BCA assay (Thermo Scientific, \# 23,225). Cytoplasmic and nuclear cell fractionation was achieved using the Pierce NE-PER ${ }^{\mathrm{TM}}$ Extraction reagents (Thermo Scientific, $\# 78,833$ ). All samples were kept at $-20{ }^{\circ} \mathrm{C}$ for short-term use, or $-80{ }^{\circ} \mathrm{C}$ for long-term storage (Table 1 ).

\section{Immunoblotting}

SDS-PAGE of 20-30 $\mu \mathrm{g}$ of protein was performed on $4-15 \%$ gradient reducing gels. Proteins were then transferred $4{ }^{\circ} \mathrm{C}$ onto PVDF membranes at $4{ }^{\circ} \mathrm{C}$ and total protein loading was measured prior to blotting using Ponceau 
Table 1 siRNA oligo pools

\begin{tabular}{llll}
\hline Target & Species & Accession & Pool (Dharmacon ${ }^{\text {TM Cat\#) }}$ \\
\hline Lats1 & R. norvegicus & NM_001134543.2 & M-080189-01-0005 \\
Lats2 & R. norvegicus & NM_001107267.1 & M-087043-01-0005 \\
Limd1 & R. norvegicus & NM_001112737.2 & L-081750-02-0005 \\
Ski & R. norvegicus & XM_017593893 & L-099478-02-0005 \\
Wwtr1 (Taz) & R. norvegicus & NM_001024869.1 & M-088521-01-0005 \\
Non-targeting pool & H. sapiens, M. musculus, & n/a & D-001810-10-05 \\
& R. norvegicus & & \\
\hline
\end{tabular}

S (Alfa Aesar, Haverhill, MA; \#J63139) staining, or after blotting using Pelikan 17 black india ink (Thomas Scientific, Swedesboro, NJ; \#C861L76). Blots were incubated with primary antibodies (listed in Table 2) overnight at $4{ }^{\circ} \mathrm{C}$ with gentle shaking. Corresponding HRP-conjugated secondary antibodies (Jackson ImmunoResearch, West Grove, PA) were applied at a 1:5000-1:20 000 dilution for $1 \mathrm{~h}$ at room temperature. Antibody detection was done using ECL substrate, and protein bands were visualized on blue X-ray film (Mandel Scientific, Guelph, ON). Protein expression was measured by relative densitometry using Quantity One analysis software (version 4.6.9; Bio-Rad).

\section{RNA isolation and quantitative PCR}

Cardiac fibroblasts were harvested by trypsinization and centrifugation at $200 \times g$ for $5 \mathrm{~min}$. Column-based total RNA isolation was performed using the PureLink RNA Mini kit (Invitrogen, Carlsbad, CA; \# 12,183,025) following the manufacturer's instructions. DNase treatment and cDNA synthesis were performed on $50 \mathrm{ng}$ of total RNA (Maxima First Strand cDNA Synthesis Kit for RT-qPCR, with dsDNase; Thermo Scientific; \#K1672), and the final product was diluted to $200 \mu \mathrm{L}$ sterile TE buffer (10 mM Tris-HCl, $1 \mathrm{mM}$ EDTA, pH 8.0) before use.

Gene expression was assayed using Luna ${ }^{\circledR}$ Universal qPCR Master Mix (New England Biolabs, Ipswich, MA; \#M3003). All reactions were performed in technical triplicates on a QuantStudio 3 Real-Time PCR System (Applied Biosystems, Foster City, CA). All samples from resting (P0, $5 \mathrm{kPa}$ plates) fibroblasts were normalized to endogenous Ywhaz expression, while samples from activated myofibroblasts (P1, plastic plates) were normalized to Hprt1. qPCR primer pairs and their targets are listed in Table 3.

\section{Plasmid expression vectors}

Mutation of human YAP and TAZ to promote nuclear translocation was performed using the QuickChange II Site-Directed Mutagenesis Kit (Agilent Technologies, Santa Clara, CA; \#200,523), with some modifications to

Table 2 List of primary antibodies used for immunoblotting

\begin{tabular}{llll}
\hline Antibody target & Host & Manufacturer & Catalogue number \\
\hline ED-A (Cellular) Fibronectin & Mouse & MilliporeSigma, Burlington, MA, USA & MAB1940 \\
QSMA & Mouse & MilliporeSigma, Burlington, MA, USA & A2547 \\
Periostin & Rabbit & Abcam, Cambridge UK & ab14041 \\
Vimentin & Mouse & Abcam, Cambridge UK & ab8069 \\
YAP & Rabbit & Cell Signaling, Danvers, MA, USA & 14,074 \\
TAZ/WWTR1 & Rabbit & Cell Signaling, Danvers, MA, USA & 83,669 \\
GAPDH & Mouse & Cell Signaling, Danvers, MA, USA & 97,166 \\
LIMD1 & Rabbit & Abcepta Inc, San Diengo, CA, USA & AP13132b \\
LATS1 & Rabbit & Cell Signaling, Danvers, MA, USA & 3477 \\
LATS2 & Rabbit & Cell Signaling, Danvers, MA, USA & 5888 \\
HA-tag & Rabbit & Rockland Immunochemicals, Limerick PA, USA & $600-401-384$ \\
MYC-tag & Rabbit & Cell Signaling, Danvers, MA, USA & 2278 \\
NCoR1 & Rabbit & Cell Signaling, Danvers, MA, USA & 5948 \\
SKI & Rabbit & Novus Biologicals, Littleton, CO, USA & NBP2-94,105 \\
TEAD3 & Rabbit & Cell Signaling, Danvers, MA, USA & 13,224 \\
\hline
\end{tabular}


Table 3 qPCR primers

\begin{tabular}{|c|c|c|c|c|c|}
\hline Gene & Species & Gene product & Accession & Forward primer $\left(5^{\prime}-3^{\prime}\right)$ & Reverse primer $\left(5^{\prime}-3^{\prime}\right)$ \\
\hline Acta2 & $R$. norvegicus & alpha-Smooth Muscle Actin & NM_031004.2 & $\begin{array}{l}\text { AGATCGTCCGTGACATCA } \\
\text { AGG }\end{array}$ & $\begin{array}{l}\text { TCATTCCCGATGGTGATC } \\
\text { AC }\end{array}$ \\
\hline $\operatorname{Ccn} 2(\operatorname{Ctg} f)$ & R. norvegicus & $\begin{array}{l}\text { Connective Tissue Growth } \\
\text { Factor }\end{array}$ & NM_022266.2 & CAAGCTGCCCGGGAAAT & CGGTCCTTGGGCTCATCA \\
\hline Collal & R. norvegicus & $\begin{array}{l}\text { Collagen Type I Alpha } 1 \\
\text { Chain }\end{array}$ & NM_053304.1 & TGCTCCTCTTAGGGGCCA & $\begin{array}{l}\text { CGTCTCACCATTAGGGAC } \\
\text { ССТ }\end{array}$ \\
\hline Colla2 & $R$. norvegicus & $\begin{array}{l}\text { Collagen Type I Alpha } 2 \\
\text { Chain }\end{array}$ & NM_053356.1 & $\begin{array}{l}\text { TGACCAGCCTCGCTC } \\
\text { ACAG }\end{array}$ & $\begin{array}{l}\text { CAATCCAGTAGTAATCGC } \\
\text { TCTTCCA }\end{array}$ \\
\hline Col3al & $R$. norvegicus & $\begin{array}{l}\text { Collagen Type III Alpha } 1 \\
\text { Chain }\end{array}$ & NM_032085.1 & $\begin{array}{l}\text { GGTTTCTTCTCACCCTGC } \\
\text { TTC }\end{array}$ & $\begin{array}{l}\text { GGTTCTGGCTTCCAGACA } \\
\text { TC }\end{array}$ \\
\hline Cthrcl & R. norvegicus & $\begin{array}{l}\text { Collagen Triple Helix Repeat } \\
\text { Containing } 1\end{array}$ & NM_172333.2 & $\begin{array}{l}\text { CTATCTGGACCAAGG } \\
\text { AAGCCC }\end{array}$ & $\begin{array}{l}\text { CAGATGGCCACGTCTACC } \\
\text { AG }\end{array}$ \\
\hline Fn1 & R. norvegicus & $\begin{array}{l}\text { Fibronectin (ED-A Splice } \\
\text { Variant) }\end{array}$ & NM_019143.2 & $\begin{array}{l}\text { ACTGCAGTGACCAACATT } \\
\text { GACC }\end{array}$ & $\begin{array}{l}\text { CACCCTGTACCTGGAAAC } \\
\text { TTGC }\end{array}$ \\
\hline Limdl & R. norvegicus & $\begin{array}{l}\text { LIM Domain containing } \\
\text { protein } 1\end{array}$ & NM_001112737.2 & $\begin{array}{l}\text { AACAGGCCTTTGGTC } \\
\text { CACTG }\end{array}$ & $\begin{array}{l}\text { GCCTCATATCCCAGACTC } \\
\text { GAA }\end{array}$ \\
\hline Hprt1 & R. norvegicus & $\begin{array}{l}\text { Hypoxanthine-Guanine Phos- } \\
\text { phoribosyltransferase }\end{array}$ & NM_012583.2 & $\begin{array}{l}\text { CTCATGGACTGATTATGG } \\
\text { ACAGGAC }\end{array}$ & $\begin{array}{l}\text { GCAGGTCAGCAAAGAACT } \\
\text { TATAGCC }\end{array}$ \\
\hline Postn & R. norvegicus & Periostin & NM_001108550.1 & $\begin{array}{l}\text { GCTTCAGAAGCCACT } \\
\text { TTGTC }\end{array}$ & $\begin{array}{l}\text { CGCCAACTACATCGACAA } \\
\text { GG }\end{array}$ \\
\hline RelA & $R$. norvegicus & $\begin{array}{l}\text { NFkB subunit RelA (Tran- } \\
\text { cription Factor p65) }\end{array}$ & NM_199267.2 & $\begin{array}{l}\text { TTCCCTGAAGTGGAGCTA } \\
\text { GGA }\end{array}$ & $\begin{array}{l}\text { CATGTCGAGGAAGACACT } \\
\text { GGA }\end{array}$ \\
\hline $\operatorname{Tcf} 21$ & R. norvegicus & Transcription Factor 21 & NM_001032397.1 & $\begin{array}{l}\text { CATTCACCCAGTCAA } \\
\text { CCTGA }\end{array}$ & $\begin{array}{l}\text { CCACTTCCTTTAGGTCAC } \\
\text { TCTC }\end{array}$ \\
\hline Wwtrl & R. norvegicus & $\begin{array}{l}\text { WW domain containing } \\
\text { Transcription Regulator } 1 \\
\text { (TAZ) }\end{array}$ & NM_001024869.1 & $\begin{array}{l}\text { ACCTGGCTGTAGTGT } \\
\text { GATGC }\end{array}$ & $\begin{array}{l}\text { CCAGGCAATGATTAAGCG } \\
\text { GC }\end{array}$ \\
\hline Yapl & $R$. norvegicus & Yes-Associated Protein 1 & NM_001034002.2 & $\begin{array}{l}\text { CAGACAACAACATGG } \\
\text { CAGGAC }\end{array}$ & $\begin{array}{l}\text { CTTGCTCCCATCCATCAG } \\
\text { GAAG }\end{array}$ \\
\hline Ywhaz & R. norvegicus & $\begin{array}{l}\text { Tyrosine 3-monooxygenase/ } \\
\text { Tryptophan 5-monooxyge- } \\
\text { nase Activation protein Zeta }\end{array}$ & NM_013011.3 & $\begin{array}{l}\text { TTGAGCAGAAGACGG } \\
\text { AAGGT }\end{array}$ & $\begin{array}{l}\text { GAAGCATTGGGGATCAAG } \\
\text { AA }\end{array}$ \\
\hline
\end{tabular}

the manufacturer's protocol, as described by Zheng et al. [64]. Both wild-type genes were cloned into pcDNA3 prior to mutagenesis. All plasmid constructs were sequenced for confirmation of the mutations (YAP S127A, TAZ S89A) and complete coverage of the insert.

\section{Luciferase reporter assay}

Proximal promoters for the human Collal (1.4 kb) and Col3al (1.5 kb) genes were generated from human genomic and subcloned into the pGL4.1[Luc2] vector. NIH-3T3 fibroblasts were seeded in 6-well dishes $24 \mathrm{~h}$ prior to transfection at a density that would yield $\sim 60 \%$ confluency. Wells were co-transfected using jetPRIME DNA transfection reagent (Polyplus Transfection, Illkirch, France; \#114-15) with $500 \mathrm{ng}$ pGL4.1[Luc2] promoter-reporter plasmid and $500 \mathrm{ng}$ expression vector for $48 \mathrm{~h}$. Cells transfected with empty expression vector with the corresponding promoter construct served as background control samples. Promoter activity was assayed using a Luciferase Reporter Assay Kit I (PromoCell GmbH, Heidelberg, Germany; \# PK-CA70730,003-1) and luciferase activity was quantified on a GloMax Multi + Multimode Plate Reader (Promega, Madison, WI). All samples were assays in triplicates and relative promoter activity was normalized to total protein concentration for the corresponding sample.

\section{Collagen gel contraction assay}

Three-dimensional collagen gels were prepared by mixing $16 \mathrm{~mL}$ of chilled collagen solution (PureCol® Type I bovine collagen; Advanced BioMatrix, Sand Diego, CA), with $2 \mathrm{~mL}$ of sterile 10X PBS. While keeping the solution on ice, the $\mathrm{pH}$ was adjusted to $7.4 \mathrm{using}$ sterile $0.1 \mathrm{M} \mathrm{NaOH}$, and the volume was brought up to $20 \mathrm{~mL}$ with sterile water. Gels were cast in a 24 -well plate by adding $600 \mu \mathrm{L}$ solution to each well and allowing them to solidify at $37{ }^{\circ} \mathrm{C}, 5 \%$ $\mathrm{CO}_{2}$ overnight. The following day, $\mathrm{P} 0$ fibroblasts cultured 
on $5 \mathrm{kPa}$ elastic surfaces were passaged and seeded on the collagen matrices at a density of $1.5 \times 10^{4}$ cells per well and allowed to adhere for $24 \mathrm{~h}$. The gels were then released from the wells using a circular cutting tool and immediately infected with their corresponding adenoviral vector, or treated with $4 \mathrm{ng} / \mathrm{mL}$ recombinant human TGF- $\beta_{1}$ (Cell Signaling, \#8915) as a positive control. Images were taken immediately following treatment, and subsequently every $24 \mathrm{~h}$ for a total of $72 \mathrm{~h}$ post-treatment. Gel contraction was estimated by measuring the surface area of the top of the gel using ImageJ image processing software [44].

\section{Wound healing assay}

Silicone inserts (Ibidi, Martinsried, Germany; \#81,176) were placed into the wells of a porcine gelatin-coated 24-well $5 \mathrm{kPa}$ elastic tissue culture dish (Excellness, as described above). $70 \mathrm{uL}$ of freshly isolated primary rat cardiac fibroblast cell suspension $\left(\sim 5.0 \times 10^{4}\right.$ cells $\left./ \mathrm{mL}\right)$ was added to each chamber of the insert, and $0.5 \mathrm{~mL}$ of F-10 medium supplemented with $2 \%$ FBS was added to the area surrounding the insert. The culture medium was changed every day for the following 3 days, after which the cells were allowed to reach $80 \%$ confluency within the insert chambers. The inserts were then removed, and the cells were infected with an MOI of 50 of their corresponding adenoviral constructs in serum-free F-10 medium. Light microscopy images were captured at 6,12 , and $18 \mathrm{~h}$ post-infection, after which percent surface area coverage was calculated using ImageJ software.

\section{Isolation of human atrial cardiac fibroblasts}

Human primary cardiac fibroblasts were obtained from male patients undergoing elective, isolated coronary artery bypass graft (CABG) surgery. Cells were isolated as previously described [41]. In brief, freshly isolated tissue was finely minced and placed in culture dishes containing basal medium supplemented with $10 \%$ fetal bovine serum (FBS), 100 units/mL penicillin and $100 \mu \mathrm{g} / \mathrm{mL}$ streptomycin. Cells were allowed to migrate from the explants for approximately 10 days prior to passaging, at which point they were maintained in complete cardiac fibroblast growth medium (FGM ${ }^{\mathrm{TM}}$, Lonza Group AG, Basel, Switzerland). Cells were passaged at least two times (P2) prior to using in experiments, and P3 cells were frozen for future use and used for BioID2 experiments.

\section{BiolD2 assay and mass spectrometry analysis}

BioID2 fusion proteins were generated from the mycBioID2-MCS plasmid and Adeno-X Adenoviral Expression System 1 (Takara Bio Inc., Kusatsu, Japan). The
myc-BioID2-MCS vector was a gift from Kyle Roux (Addgene plasmid \# 74,223; http://n2t.net/addgene:74223; RRID:Addgene_74223). In vitro biotinylation assays were performed on primary human cardiac fibroblasts; cells passaged three times (P3) were used in BioID2 assays, and were considered as activated myofibroblasts.

Once at approximately $40 \%$ confluency, cells were switched to serum-free F10 medium, and infected with an MOI of 20 of either: Ad-myc-BioID2-Empty, Ad-mycBioID2-hSKI, or Ad-myc-BioID2-hTAZ. After $24 \mathrm{~h}$, the medium was supplemented with $20 \mu \mathrm{M}$ biotin from a freshly prepared $100 \mathrm{X}$ stock diluted in warm culture medium. Finally, after further incubation for $18 \mathrm{~h}$, the medium was removed and the cells were briefly washed twice with roomtemperature $1 \mathrm{X}$ phosphate buffered saline (PBS). Cells were lysed with $500 \mu \mathrm{L}$ lysis buffer (1\% NP-40; 0.5\% deoxycholate; $0.2 \%$ SDS; $2 \%$ Triton X-100; 50 mM Tris $\mathrm{HCl}, \mathrm{pH} 7.4$; 150 mM NaCl; 1 mM EDTA; $10 \%$ glycerol; supplemented with $1 \mathrm{X}$ Sigma protease inhibitor cocktail P8340). Samples were briefly sonicated, and then, samples were then diluted with an equal volume of $50 \mathrm{mM}$ Tris $\mathrm{HCl}, \mathrm{pH} 7.4$ and incubated overnight on a rotator at $4{ }^{\circ} \mathrm{C}$ with $400 \mu \mathrm{L}$ of magnetic streptavidin beads (\#S1420S, New England Biolabs, Ipswich, MA) that had been pre-washed for $10 \mathrm{~min}$ in lysis buffer. The following day, the beads were washed once in $2 \% \mathrm{SDS}$ for $10 \mathrm{~min}$, followed by four times for $10 \mathrm{~min}$ each in $50 \mathrm{mM}$ Tris $\mathrm{HCl}, \mathrm{pH}$ 7.4. The beads were resuspended in $1 \mathrm{~mL}$ wash buffer, and $20 \%$ was saved for analysis by Western blot. The remaining beads were resuspended in 250 $\mu \mathrm{L}$ of $50 \mathrm{mM} \mathrm{NH} \mathrm{NCO}_{3}$ and sent for mass spectrometry analysis at the Manitoba Centre for Proteomics and Systems Biology (Winnipeg, MB, Canada).

Samples isolated by BioID2 pulldown were subject to tryptic digestion, and digested peptide solutions for each biological replicate was subject to two technical replicate analyses on a Q Exactive ${ }^{\mathrm{TM}} \mathrm{HF}-\mathrm{X}$ Orbitrap mass spectrometer (Thermo Scientific, Waltham, MA) in standard tandem MS/MS with data-dependent acquisition. The protein identification parameters were as follows: minimum fragment $\mathrm{M} / \mathrm{Z}$ of 100 ; precursor mass tolerance of $\pm 10 \mathrm{ppm}$; fragment mass error of $0.02 \mathrm{Da}$, and a maximum $E$ value of 0.01. Fixed modifications for oxidation of methionine and tryptophan, deamination of asparagine and glutamine, and carboxyamidomethylation of cysteine were also included in the analytical parameters. Peptides were compared against the SwissProt human protein database and were identified and quantified using $\mathrm{X}$ !tandem (Alanine, 2017.02.01). Proteins with fewer than 3 spectral counts, common background and contaminating proteins (e.g., keratins, histones, trypsin) were excluded from the resulting data. Technical replicates were then combined for interactome analysis.

Significance of interaction between bait (SKI or TAZ) and prey was determined using probabilistic scoring via the 

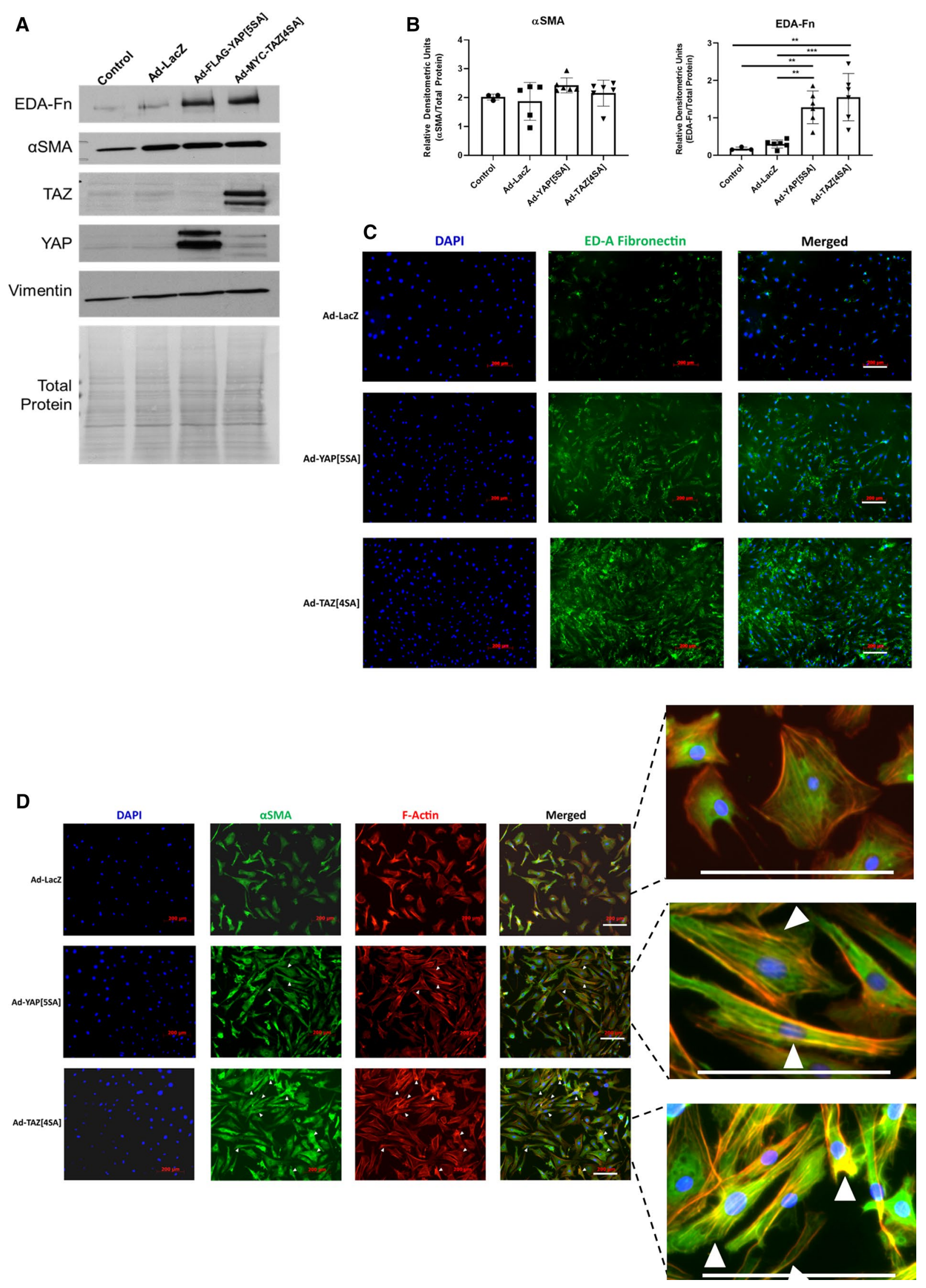
४Fig. 1 YAP and TAZ induce cardiac myofibroblast marker expression. a Immunoblotting of whole cell lysates from unpassaged (P0) primary rat cardiac fibroblasts cultured on $5 \mathrm{kPa}$ elastic silicone tissue culture surfaces coated with gelatin. Cells were treated with adenoviral constructs overexpressing constitutively active forms of YAP (AdFLAG-YAP[5SA]), TAZ (Ad-MYC-TAZ[4SA]), or Ad-LacZ controls for approximately $36 \mathrm{~h}$. b Quantification of densitometric measurements represented in panel A ( $n=3$ untreated controls; $n=6$ biological replicates per test condition). Data are presented at mean \pm SD. $* P<0.05$ versus untreated and Ad-LacZ infected controls. c P0 primary rat cardiac fibroblasts cultured on $5 \mathrm{kPa}$ elastic silicone coverslips were infected with constitutively active Ad-YAP[5SA], AdTAZ[4SA], or Ad-LacZ for $36 \mathrm{~h}$ prior to fixation and for indirect immunofluorescence detection of fibronectin extracellular domain splice variant A (ED-A FN; green); nuclei were counterstained with DAPI (blue). Scale bar $=200 \mu \mathrm{m}$. d P0 primary rat cardiac fibroblasts treated as described for panel $\mathrm{C}$, with indirect immunofluorescence detection of alpha-Smooth Muscle Actin ( $\alpha$ SMA; green) and F-actin (phalloidin staining; red). White arrows indicate cells with greater inclusion of $\alpha \mathrm{SMA}$ into F-actin stress fibers. Data shown for C and D are representative of $n=3$ biological replicates

Significance of Analysis of Interactome express (SAINTexpress) algorithm [53]. Using the Contaminant Repository for Affinity Purification (CRAPome.org) [37], SAINTexpress was applied to the data sets using user-uploaded (untreated and empty BioID2 vector) controls, incorporation of iRefIndex data, and using all replicates per bait. SAINT scores and fold-change values for both SKI and TAZ are displayed in Supplemental Tables 1 and 3 respectively. Proteins included in the final interactomes had a fold change of $\geq 3$ compared to empty-BioID2 and untreated controls, and obtained a SAINT score $\geq 0.5$. Our rationale for lowering the SAINT score was due to the fact that there exists no repository for primary human cardiac fibroblast protein interactions, and the vast majority of proximity-labelling data that is publicly available has been gathered in cell lines. The resulting data were then formatted for use in Cytoscape (version 3.7.1) to generate interaction network graphics, and Gene Ontology (GO) and pathway analyses were performed using the STRING database (version 11.0) and WikiPathways (wikipathways.org) [28]. Finally, novel interactions were confirmed by repeated affinity capture and probing for targets by immunoblotting. Data were generated using cells isolated from $n=4$ biological samples.

The mass spectrometry proteomics data have been deposited to the ProteomeXchange Consortium via the PRIDE partner repository with the data set identifier PXD018246. To access the data, the following login information may be used: Username: reviewer00088@ebi.ac.uk Password: A7zMZkwM. A copy of the data has also been included in the online data supplement.

\section{F/G actin isolation and fractionation}

Cardiac myofibroblasts were cultured and treated in $10 \mathrm{~cm}$ dishes, and harvested at $\sim 50-60 \%$ confluency. Cells were washed twice in pre-warmed 1X PBS to remove any excess medium and serum. After removing as much PBS as possible, $F$ and $G$ actin were isolated using a G-actin/F-actin in vivo Assay Kit (Cytoskeleton Inc., Denver, CO; \#BK037), as per the manufacturer's directions. Immunoblotting was performed with pan-actin antibody (1:1000; Cell Signaling; \#4968), and peroxidase-conjugated goat anti-rabbit secondary antibodies (1:10 000; Jackson ImmunoResearch).

\section{Fluorescence immunohistochemistry (IHC-F)}

Frozen OCT-preserved tissues were cut into $6 \mu \mathrm{m} \mathrm{sec-}$ tions using a cryostat microtome and mounted on glass slides which were kept in a Coplin jar on ice. Sections were allowed to air dry and adhere to the slides for $30 \mathrm{~min}$ while remaining on ice. The slides were then washed twice for 5 min with warm PBS to remove as much OCT as possible.

Tissue sections were fixed in $4 \%$ paraformaldehyde in 1X PBS (pH 7.4) for $10 \mathrm{~min}$, after which they were washed in neutralizing buffer (0.4 M Glycine in $1 \mathrm{X}$ PBS, $\mathrm{pH}$ 7.4) twice for $5 \mathrm{~min}$ each. Sections were then permeabilized for $15 \mathrm{~min}$ at room temperature in $0.1 \%$ Triton X-100 in PBS. Non-specific binding sites were then blocked for $30 \mathrm{~min}$ in 5\% Normal Goat Serum (Invitrogen, \# 50-197Z) in PBS. Primary antibodies were diluted in $1 \%$ Bovine Serum Albumin (Alfa Aesar, \#J64655) in PBS with $0.05 \%$ Triton X-100 to their appropriate concentration. The following antibodies were used-YAP (1:100; Cell Signaling; \#14,074), TAZ/ WWTR1 (1:100; Cell Signaling; \#4883S), and Periostin (1:100; LSBio, Seattle, WA; \#LS-B 10443). Sections were incubated in YAP or TAZ primary antibody solutions overnight $(\sim 18 \mathrm{~h})$ at $4{ }^{\circ} \mathrm{C}$. After multiple 5-min washes in PBS, Alexa Fluor-conjugated secondary antibodies (488 goat antirabbit, Invitrogen, \#A27034) were applied at a 1:500 dilution in the same dilution buffer as the primary antibodies, and incubated at room temperature for $90 \mathrm{~min}$. After several 5-min washes, the sections were incubated with Periostin primary antibody conjugated to the Alexa Fluor 594 fluorophore (Lightning-Link®; Abcam; \#ab269822) at room temperature for $90 \mathrm{~min}$. After several washes over a 45-min period, glass coverslips were applied with $20 \mu \mathrm{L}$ mounting medium with DAPI (Invitrogen, \#P36971) per section. Slides were allowed to cure overnight at room temperature, and sections were imaged with a Zeiss LSM 5 Pa microscope; images were acquired and processed using AxioVision Microscopy software (Zeiss, rel. 4.8). 
A
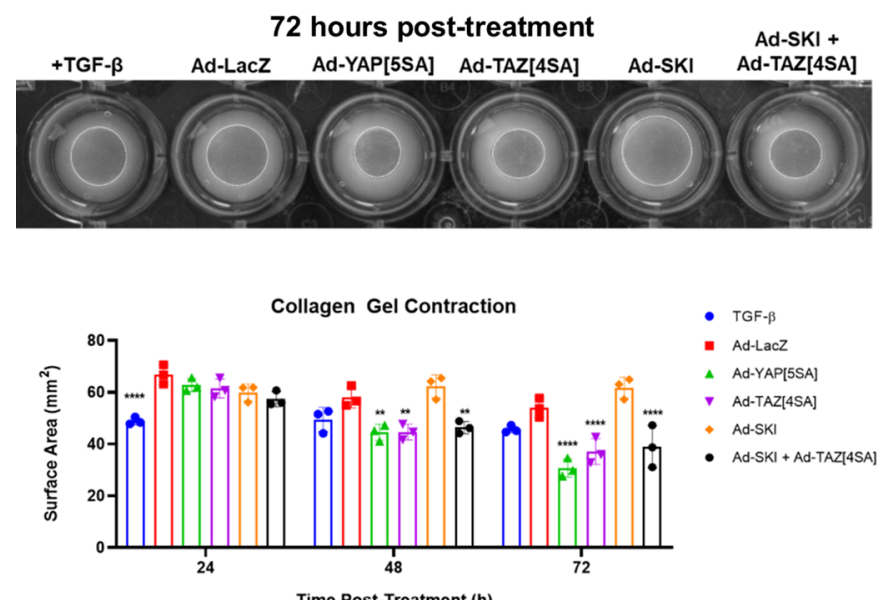

C
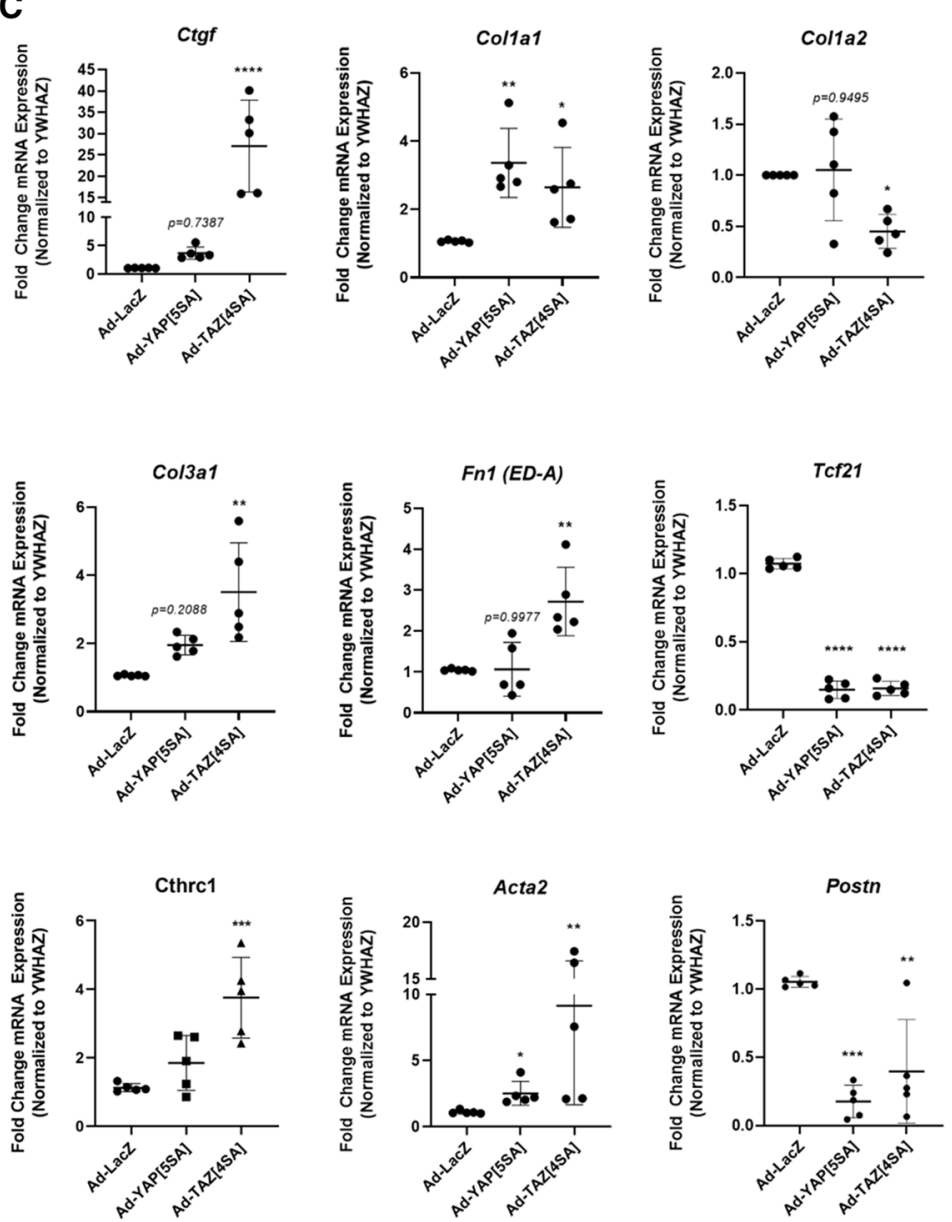
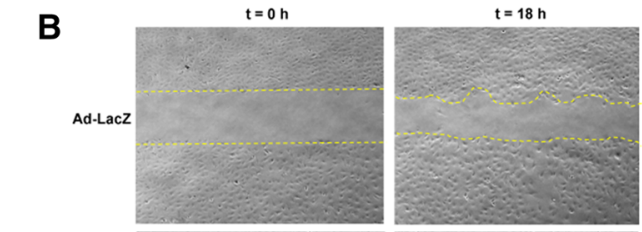

Ad-MYC-TAZ[4SA]

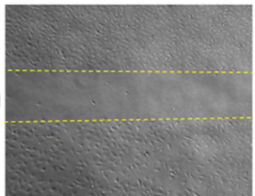

Wound Healing (18h)

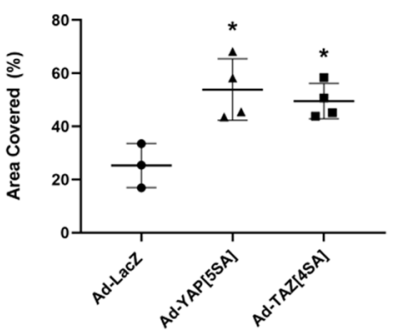

D
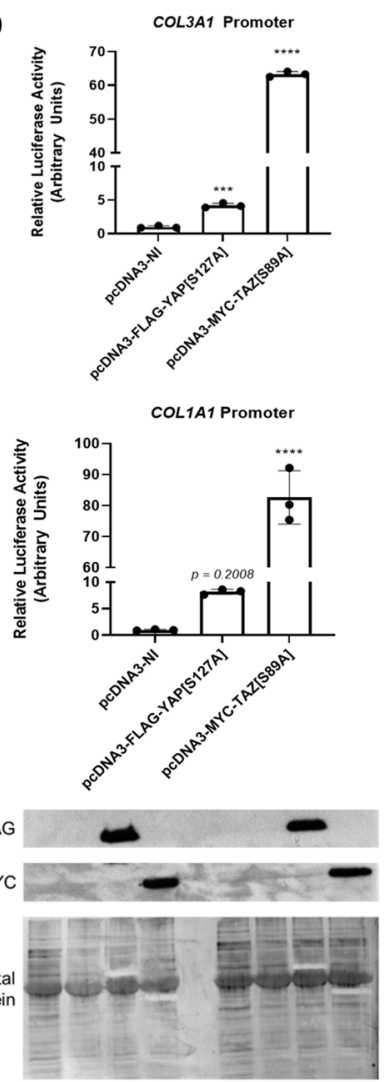

pGL4.1[luc2]-Col1a1 prom

pCDNA3 (no insert)

pcDNA3-FLAG-YAP[S127A
pcDNA3-MYC-TAZ[S89A] 
४Fig. 2 Cardiac myofibroblast gene expression and physiology are enhanced by TAZ expression. a P0 rat cardiac fibroblasts seeded on two-dimensional collagen matrices were assayed for gel contraction following infection with Ad-YAP[5SA], Ad-TAZ[4SA], Ad-SKI, a combination thereof, or with Ad-LacZ control. Treatment with recombinant human TGF- $\beta_{1}$ served as a positive control. Images were captured at 24,48 , and $72 \mathrm{~h}$ post-treatment; the image in the upper panel was captured at the 72-h timepoint. The lower panel displays the quantification of the surface area of the top of the collagen matrices, measured in $\mathrm{mm}^{2}$. Data shown are representative of $n=4$ biological replicates, where $* * P<0.01$, $* * * * P<0.0001$ when compared to Ad-LacZ infected controls. b Rat cardiac fibroblasts seeded into inserts with a defined cell-free gap on $5 \mathrm{kPa}$ elastic silicone surfaces were infected with either YAP[5SA], TAZ[4SA], or LacZ-expressing adenoviral constructs at an MOI of 50. Wound healing rate was assessed as percent surface area covered by cells at $18 \mathrm{~h}$ post-infection. Data are representative of $n=4$ biological replicates, with $* P<0.05$ when compared to Ad-LacZ infected controls. c P0 primary rat cardiac fibroblasts cultured on $5 \mathrm{kPa}$ elastic silicone tissue culture surfaces coated with gelatin were transduced with adenoviral constructs overexpressing Hippo effectors, Ad-YAP[5SA] or Ad-TAZ[4SA], or Ad-LacZ control. mRNA was isolated $48 \mathrm{~h}$ postinfection, and analyzed by qRT-PCR, with $n=5$ biological replicates per condition. Data are reported as mean fold-change with respect to Ad-LacZ infected controls. ${ }^{*} P<0.05$, $* * P<0.01$, $* * * P<0.001$, $* * * * P<0.0001$ when compared to Ad-LacZ infected controls. d NIH-3T3 fibroblasts were transfected with either an empty pcDNA3NI (NI, no insert), -YAP[S127A], or -TAZ[S89A] expressing vectors in conjunction with a luciferase reporter-promoter plasmid (pGL4.1[luc2]) containing either the human Collagen $1 \alpha 1$ (COL1A1) or $3 \alpha 1$ (COL3A1) promoter. Luciferase activity was assayed $48 \mathrm{~h}$ post-transfection, and normalized to pcDNA3 transfected controls. Data are representative of $n=3$ biological replicates (3 technical replicates each), with $* * * P<0.001, * * * * P<0.00001$ when compared to pcDNA3-transfected controls. All data (A-D) are reported as mean $\pm \mathrm{SD}$

\section{Fluorescence immunocytochemistry (ICC-F)}

Cells were seeded at a low $(\sim 10-15 \%)$ confluency onto either glass coverslips in 6-well dishes, or elastic (5 kPa) silicone coverslips (ExCellness) in $35 \mathrm{~mm}$ dishes, coated with porcine gelatin type A. After appropriate treatments, the cells were briefly washed in PBS and fixed in warm 4\% paraformaldehyde in PBS, pH 7.4 for $15 \mathrm{~min}$. After another two brief washes in PBS, cells were permeabilized and nonspecific binding sites were blocked for $1 \mathrm{~h}$ in $5 \%$ normal goat serum (Invitrogen) in PBS with $0.1 \%$ Triton X-100. Primary antibodies diluted in $1 \%$ bovine serum albumin (BSA) in PBS were applied overnight at $4{ }^{\circ} \mathrm{C}$. The following primary antibodies were used: $\alpha \mathrm{SMA}$ (1:200; Sigma; \#A2547), YAP (1:100; Cell Signaling; \#14,074), TAZ/ WWTR1 (1:100; Cell Signaling; \#4883S), ED-A fibronectin (1:100; Millipore Sigma; \#MAB 1940), LIMD1 (1:100; R\&D Systems, Minneapolis, MN; \#MAB8494), SKI (1:100; Santa Cruz; \#sc-33693). The following day, the cells were washed three times in PBS and incubated with Alexa Fluor fluorophore-conjugated secondary antibodies at 1:100 dilution for $1 \mathrm{~h}$ at room temperature: 488 rabbit anti-mouse
(Invitrogen, \#A27023), 647 rabbit anti-mouse (Invitrogen, \#A27029), 488 goat anti-rabbit (Invitrogen, \#A27034). For the samples stained for $\alpha \mathrm{SMA}$, after the initial incubation with secondary antibodies, F-actin was stained using a 1:500 dilution of rhodamine-phalloidin (R415; Invitrogen) in PBS for $30 \mathrm{~min}$. The coverslips were mounted on glass slides using mounting medium with DAPI (Invitrogen, \#P36971) and allowed to cure at room temperature for $24 \mathrm{~h}$. Coverslips were then sealed, and cells were imaged using a Zeiss LSM $5 \mathrm{~Pa}$ microscope as described above.

\section{Data analysis and statistics}

Statistical analyses and graphic data representations were primarily generated using GraphPad Prism 8 (version 8.1.2; May 2019). All data are represented by the mean \pm standard deviation, unless otherwise indicated in the figure legends. Individual biological replicates (n values) are defined as originating from experiments involving cells or tissue from one single animal or human donor. Biological replicates from assays involving cell lines were defined as having originated from cells from different passages. Data distribution was assessed by the Shapiro-Wilk test. Non-parametric grouped data analyses were performed using Kruskal-Wallis tests. Grouped data with normal distribution $(P>0.05$ Shapiro-Wilk test) were analyzed by one- or two-way ANOVA with Tukey's post hoc test for multiple comparisons or Dunnet's post hoc test when performing multiple comparisons to the controls only. In vivo data were analyzed with right (RV) and left ventricles (LV) as separate groups. Sham RV and MI RV were compared using two-way ANOVA with Sidak correction, while sham LV, viable MI viable LV and MI Scar LV were analyzed by two-way ANOVA with Dunnett's correction. Experiments involving only one control and one test condition were analyzed by $t$ tests. Significance was recorded if $P<0.05$.

\section{Results}

\section{TAZ activates the synthetic cardiac myofibroblast phenotype}

When plated on inert elastic substrata, primary cardiac fibroblasts retain a quiescent, fibroblast-like phenotype for several days in two-dimensional culture [32]. To determine whether YAP and/or TAZ are contributors to cardiac fibroblast activation, we assessed whether either can overcome culture conditions which promote the fibroblast phenotype. Primary rat cardiac fibroblasts were treated with adenoviruses which expressed constitutively active forms of human YAP and TAZ which resist phosphorylation and are expressed as predominantly nuclear proteins. Serine residues were modified 


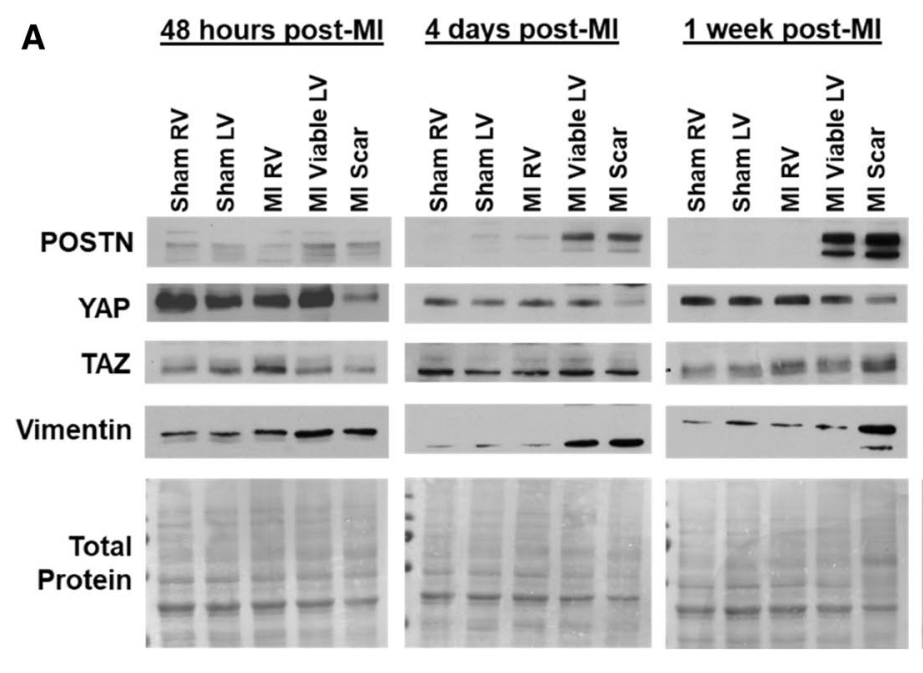

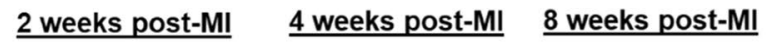

B
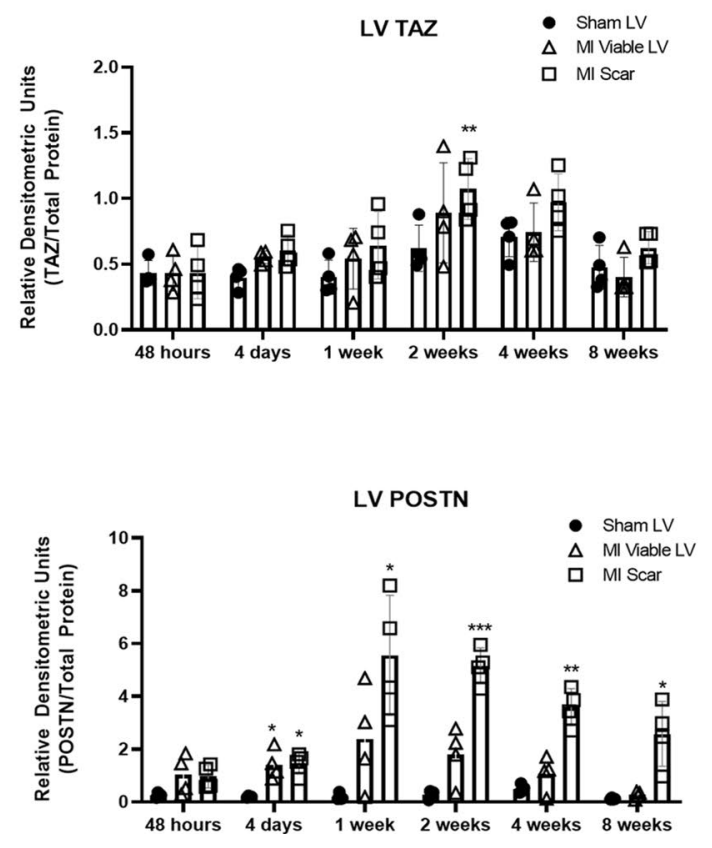

Fig. 3 YAP and TAZ expression during post-MI fibrogenesis, in vivo. a Immunoblotting of whole tissue lysate from male Sprague-Dawley rats subject to left anterior descending (LAD) coronary artery ligation or sham operation. Hearts were excised at various timepoints, spanning $48 \mathrm{~h}$ to 8 -week post-ligation, and tissue from left (LV) and right (RV) ventricles were isolated for analysis. b Quantification of densi-

to alanine as previously reported $[13,35]$ : for YAP, S61A, S109A, S127A, S164A, and S397A (YAP[5SA]) [47]; for TAZ, S66A, S89A, S117A, and S311A (TAZ[4SA]) [33]. This was done for two reasons: first, the baseline expression of both YAP and TAZ in cardiac fibroblasts cultured on soft substrates is very low and nearly undetectable on Western blots; second, overexpressed wild-type YAP and TAZ are subject to rapid phosphorylation and degradation, yielding results consistent with a dominant-negative mutant. In primary cardiac fibroblasts, overexpression of the tometric measurements of data shown in A. Data are representative of experiments originating from $n=4$ to 6 animals per timepoint, and are reported as the mean $\pm \mathrm{SD}$. $* P<0.05, * * P<0.01, * * * P<0.001$, when compared to that tissue's (RV or LV) corresponding sham animals

constitutively active forms of both YAP and TAZ yielded similar increases in ED-A FN protein expression; the change was slightly more pronounced with TAZ, but the results varied among biological replicates (Fig. 1a-c). In addition, when Taz was targeted with siRNA, its elimination also led to the inhibition of EDA-FN expression (Supplemental Fig. 1). Conversely, there was no apparent change in overall $\alpha$ SMA protein expression with overexpression of either YAP or TAZ when compared to Ad-LacZ infected controls. While total $\alpha$ SMA expression was unchanged, its inclusion 
in cytoplasmic stress fibers was increased with both YAP and TAZ overexpression, despite the cells being plated on $5 \mathrm{kPa}$ elastic culture surfaces (Fig. 1d). Furthermore, twodimensional gel contraction assays indicated that there was indeed an increase in the contractility of both YAP[5SA] and TAZ[4SA]-overexpressing fibroblasts, when compared to LacZ and SKI-overexpressing controls (Fig. 2a). It was also observed that when overexpressed in conjunction with TAZ[4SA], SKI's ability to inhibit the contractile myofibroblast phenotype was nearly completely abrogated; this suggests that SKI's mechanism to regulate TAZ is dependent on its phosphorylation state. In addition, the wound-healing rate of unpassaged (P0) primary cardiac fibroblasts was increased twofold with both active YAP and TAZ overexpression, as demonstrated by in vitro wound healing assays (Fig. 2b)

Quantitative PCR further confirmed the activation state of primary cardiac fibroblasts treated with either YAP[5SA] or TAZ[4SA] (Fig. 2c). Initial investigations probed for Ctgf, Acta2 ( $\alpha \mathrm{SMA}$ ), and Fnl (ED-A splice variant) and revealed that TAZ overexpression in primary cardiac fibroblasts resulted in an acute increase in both $C \operatorname{tg} f$ and $F n l$ transcription. While both YAP and TAZ demonstrated at least a twofold increase in Acta2 transcription, the increase showed greater variance with TAZ. We next probed $\operatorname{Tc} f 21$, a marker of quiescent resident cardiac fibroblasts which has been shown to decrease in expression during fibrogenesis $[17,26]$. Active YAP and TAZ overexpression markedly reduced $T c f 21$ transcription, compared to LacZ-overexpressing controls. We also probed for periostin (Postn), but did not observe any changes in its transcription. We have found that Postn is not a reliable marker for in vitro fibroblast activation in the absence of exogenous TGF- $\beta 1$ treatment (data not shown). Finally, we examined collagen transcription, specifically for fibrillar monomers $1 \alpha 1,1 \alpha 2$ and $3 \alpha 1$. With both YAP and TAZ activation, Collal transcription was increased, and yet only TAZ significantly increased Col3al expression. In contrast to this was Colla2, which showed no transcriptional modulation with YAP, but was found to slightly decrease with TAZ overexpression. In concert with these findings, Collagen Triple Helix Repeat-Containing 1 (Cthrcl) transcript expression was also increased with YAP and TAZ activation, suggesting that these factors indeed contribute to myofibroblast activation and extracellular matrix remodelling. To further examine the role of YAP/ TAZ on fibrillar collagen transcription, luciferase assays for the human $C O L 1 A 1$ and $C O L 3 A 1$ promoters was performed in NIH-3T3 fibroblasts (Fig. 2d). Upon induction of active YAP expression, the activity of the COLIAI and COL3AI promoters was increased by approximately eightfold and fourfold, respectively. A stark contrast was observed with active TAZ induction, which yielded over 10 times greater luciferase activity from both promoters, when compared to active YAP. Overall, these data suggest that while both YAP and TAZ do induce a more myofibroblast-like phenotype, TAZ may play a greater role to the incorporation of $\alpha \mathrm{SMA}$ into stress fibers and the increased production of fibrillar collagens.

\section{TAZ expression increases during post-MI fibrogenesis}

To interrogate the role of YAP/TAZ in cardiac fibrogenesis, we implemented a rat post-MI model of acute replacement fibrosis to observe their expression over time. Tissue was collected from rats subject to left anterior descending (LAD) coronary ligation or sham surgery at the following timepoint post-infarct: 48 h, 4 days, 1 week, 2 weeks, 4 weeks, and 8 weeks. In addition, heart tissue was further isolated into individual components for examination: sham left $(\mathrm{LV})$ and right (RV) ventricles, along with LAD ligated RV, viable $\mathrm{LV}$, and LV scar. Using periostin as a marker of fibroblast activation and active matrix remodelling, and vimentin as an indicator of mesenchymal cells, we probed for YAP and TAZ individually at each timepoint. Immunoblotting revealed that TAZ expression peaks at the 2-week timepoint in concert with periostin and vimentin (Fig. 3a), and remains above baseline levels until 4-week post-MI. In sections used for immunofluorescence studies, we found some punctate expression of TAZ and strong periostin staining in the infarct scar. We cannot definitively conclude that the increase in TAZ expression is originating from activated myofibroblasts, as we observed only punctate staining in the expanding infarct scar (Fig. 4b and Supplemental Fig. 5). We also observe TAZ staining in the perivascular medial space and in surviving cardiomyocytes of the myocardium bordering the infarct scar. Furthermore, our data show punctate periostin expression the infarct scar (Fig. 4b and Supplemental Fig. 5). Conversely, YAP expression remains relatively unchanged among all timepoints; however, there is a modest decrease at 2-week post-MI, and an upward trend in the later phases of post-MI remodeling (Fig. 3a, b). When probing tissue sections by immunofluorescence 2-week postMI, we found that YAP expression shifts from cardiomyocyte-specific expression to reduced levels in infarct scar and border zone tissues (Fig. 4a and Supplemental Fig. 5). between infarcted and sham-operated LV tissue (Fig. 4a, top panels), but is increased in expression in the vascular media. There is sparse YAP staining within the infarcted $\mathrm{LV}$, and periostin is localized to the central, maturing portion of the infarct scar. TAZ expression is markedly enriched in the border zone tissue with punctate staining in the infarct scar (Fig. 4b; Supplemental Fig. 5). There was also significant TAZ staining in the perivascular media and adventitia, although co-staining in areas which are periostin-positive was seldom seen. In sham-operated tissue, TAZ was largely 

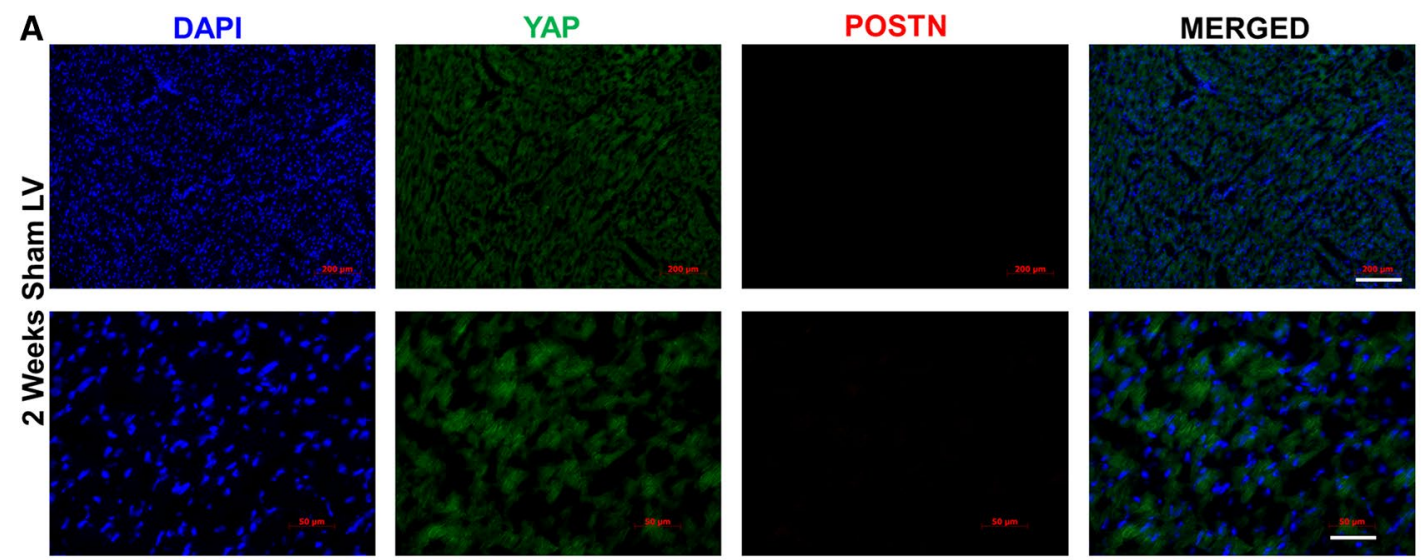

$10 x$
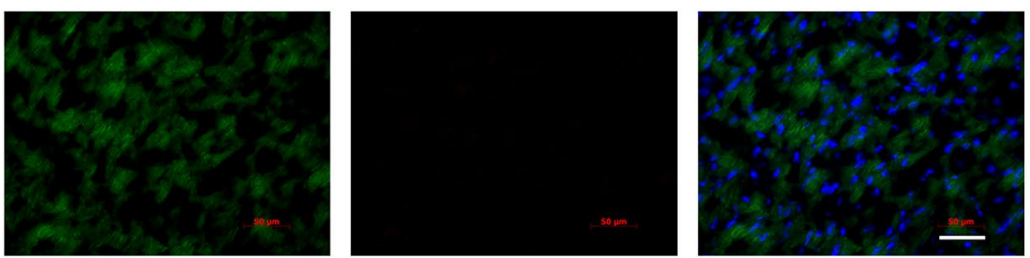

$40 x$
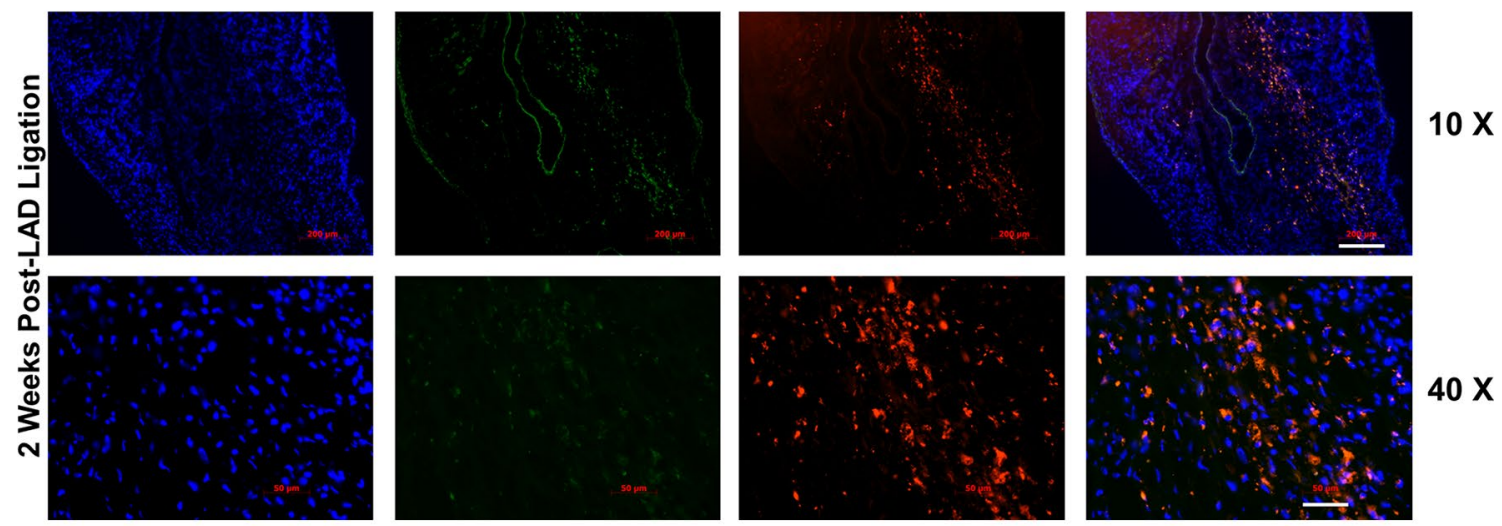

$40 x$
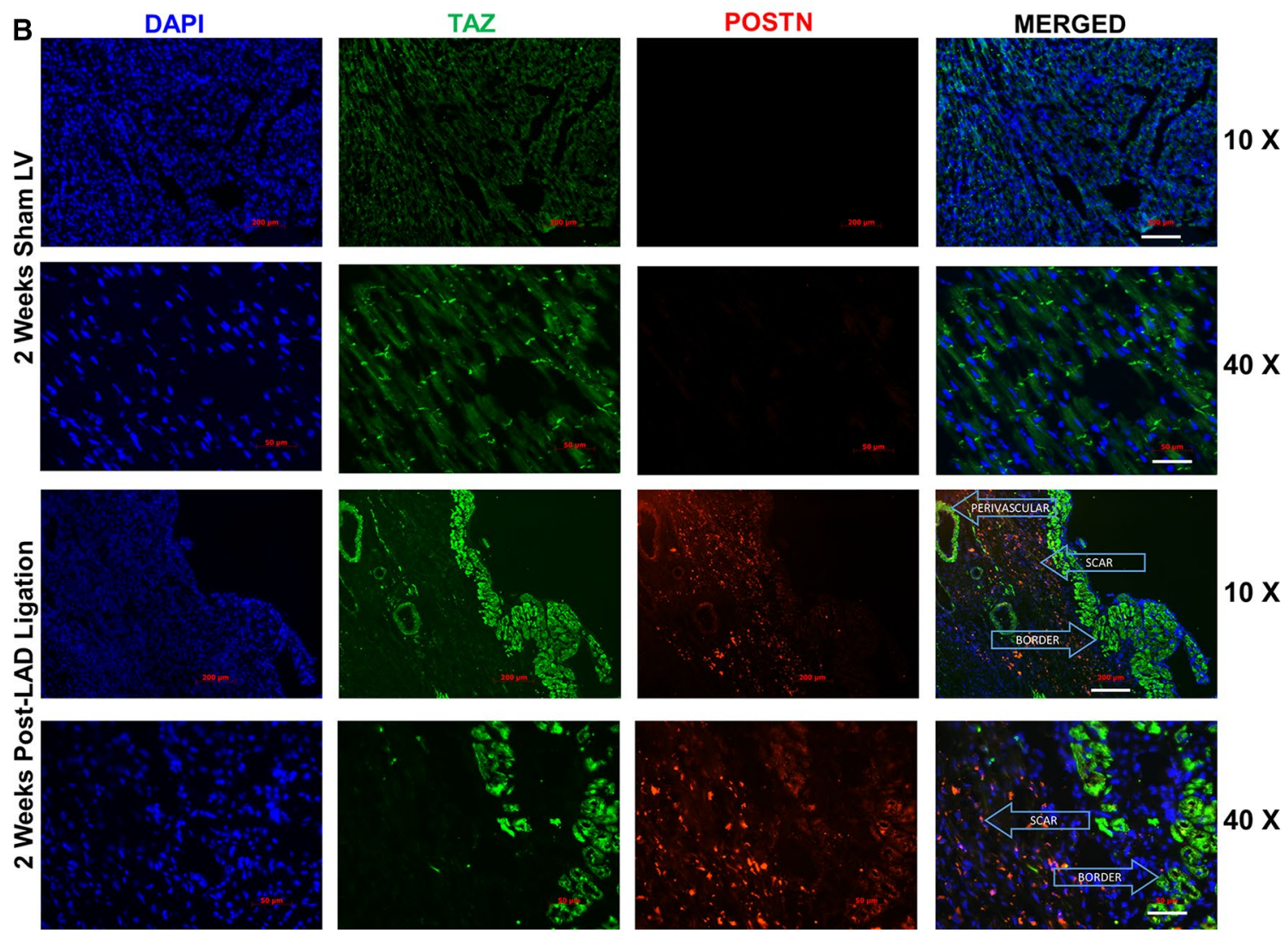

$0 x$

$40 x$
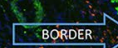

$10 x$

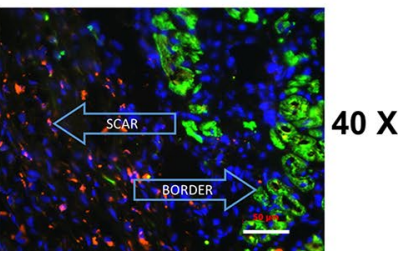


4Fig. 4 TAZ expression is increased in the surviving noninfarcted myocardium adjacent to the infarct scar and in the infarct scar following MI. Indirect immunofluorescence of LV scar at 2-week post-MI (LAD ligation) or sham operation. Sections were probed for YAP (A panels, green), or TAZ (B panels, green) and extracellular periostin (POSTN-red) for identification of areas containing remodeling tissues. Perivascular medial tissues and infarct scar are indicated with arrows. Periostin staining was apparent in the infarct scar in 2-week post-LAD ligation group. TAZ staining was observed in the Z-line regions of myocytes of noninfarcted control heart sections, and in the perivascular space, surviving myocytes of the border zone myocardium and in the infarct scar. Nuclei were counterstained with DAPI (blue). Scale bars $=200 \mu \mathrm{m}$ at $10 \mathrm{X}$ magnification, and $50 \mu \mathrm{m}$ at $40 \mathrm{X}$ magnification. Images are representative of $n=3$ biological replicates

expressed at intercalated discs within cardiomyocytes, and this distinct characteristic feature was subject to redistribution upon infarction (Fig. 4b). It was not evident with YAP or TAZ whether nuclear localization of endogenous protein was altered during post-MI remodeling. Both YAP and TAZ have altered myocardial expression during post-MI remodeling, and we note the presence of some TAZ staining in the infarct scar, with greater staining in the medial perivascular space and surviving cardiomyocytes of the border zone (Fig. 4b and Supplemental Fig. 5). We also observed marked punctate staining of periostin in the infarct scar.

\section{SKI induces proteasomal degradation of TAZ, but not YAP}

After establishing TAZ as an important element in cardiac fibroblast activation and post-MI remodeling, we determined the effects of SKI on the Hippo pathway by overexpressing it in primary cardiac myofibroblasts. Fibroblasts isolated from healthy rat myocardium were passaged once (P1) to induce the myofibroblast phenotype, and subsequently infected with adenovirus expressing SKI. Immunoblotting of whole cell lysates and subcellular fractions revealed that the overexpressed SKI is predominantly nuclear and that SKI specifically effects a sharp downregulation of TAZ protein expression (Fig. 5a, b). In contrast, a modest upregulation of YAP expression (NS) was observed with SKI overexpression. As SKI is known to be a genetic co-repressor, we sought to rule out that this resulting attenuation in TAZ expression was controlled at the transcriptional level. qPCR analyses of SKI-overexpressing myofibroblasts revealed that both Yap and $T a z$ transcription were unaffected by ectopic SKI. However, Ctgf, a known genetic target of YAP/TAZ, exhibited a threefold reduction in transcription; this further bolstered the hypothesis that SKI regulates TAZ at the level of the protein (Fig. 5c). Finally, when examining Taz and Ctgf transcription after RNAi-induced knockdown of Ski in P0 fibroblasts cultured on soft substrates, the absence of SKI was insufficient in promoting further activation of the myofibroblast phenotype upon treatment with recombinant TGF- $\beta_{1}$
(Supplemental Fig. 3b). Untreated cells expressed low levels of $C t g f$, which markedly increased with TGF- $\beta_{1}$ treatment, but this increase in expression was unaffected by $S k i$ knockdown. Moreover, the introduction of TGF- $\beta_{1}$ did not change Taz expression, and this was also unaffected when combined with Ski-targeting siRNA. The lack of transcriptional response to $S k i$ knockdown suggests that SKI is indeed not implicated in regulating Taz transcription. These findings also confirm that SKI is only one part of a complex regulatory mechanism which governs cardiac fibroblast response to TGF- $\beta_{1}$ stimulation, and that the pleiotropic pathway has multiple avenues-mechanosensory, extracellular, and intracellular-by which it affects response to injury.

To better elucidate the mechanism by which SKI downregulates TAZ protein expression, we treated SKI-overexpressing primary cardiac myofibroblasts with various small molecule inhibitors to probe various points in the Hippo signaling cascade. We first treated cells with the pan-acting MG132 proteasome inhibitor, which yielded modest results in rescuing SKI-mediated TAZ degradation (Fig. 5d). Next, we inhibited the $\beta-\operatorname{TrCP} 1 \mathrm{E} 3$ ubiquitin ligase, a known regulator of YAP/TAZ expression, using GS143. In contrast to MG132, the downregulation of TAZ protein expression was apparently exacerbated by the inhibition of $\beta$-TrCP1. Lastly, we sought to inhibit casein kinase 1 (CK1), which works subsequent to LATS1/2 kinases to form the TAZ phosphodegron in canonical Hippo signaling [34]. Using the CK1 inhibitor, D4476, we observed TAZ degradation with SKI overexpression. The results did not coincide with MG132 treatment, and this is likely due to the pleiotropic nature of CK1, and that it may not be necessary for all instance of phosphorylation-dependent proteasomal degradation of TAZ. This, in concert with the inability of SKI to prevent TAZ[4SA]-mediated cell contraction (Fig. 2a), indicates that SKI indirectly modulates the phosphorylation state and thus the stability of TAZ.

LATS1/2 function in relation to SKI expression was examined in vitro by selectively reducing either LATS1 or LATS2 expression using RNA interference (RNAi). Using siRNA pools, either LATS1 or LATS2 expression was knocked down in primary cardiac myofibroblasts with attending ectopic SKI expression (Fig. 5b, e). SKI overexpression (MOI 10 or 20) in baseline conditions, was associated with downregulated TAZ protein levels (without LATS1 or LATS2 knockdownFig. 5b). LATS2 knockdown was associated with "protection" of TAZ expression in the presence of SKI overexpression (Fig. 5e panel 2). Knocking down LATS1 alone did not protect the SKI-mediated downregulation of TAZ. We, therefore, suggest that LATS1 is not required for SKI-mediated degradation of TAZ. We also note in the BioID2 experiment that only LATS2 appeared within in the TAZ interactome, but LATS1 did not - thus TAZ does not interact with LATS1 (Fig. 7c). Furthermore, we noted that the inclusion of nonspecific siRNA 
A
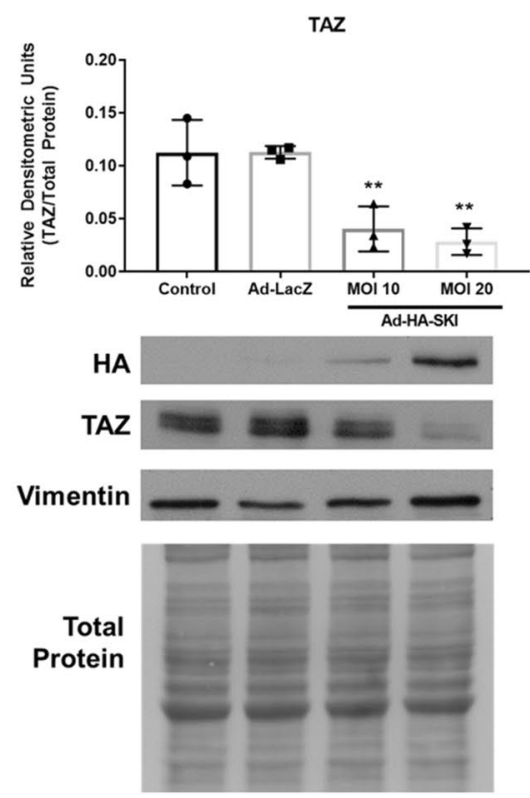

C

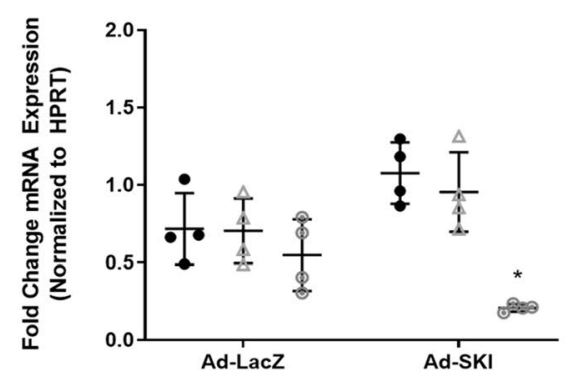

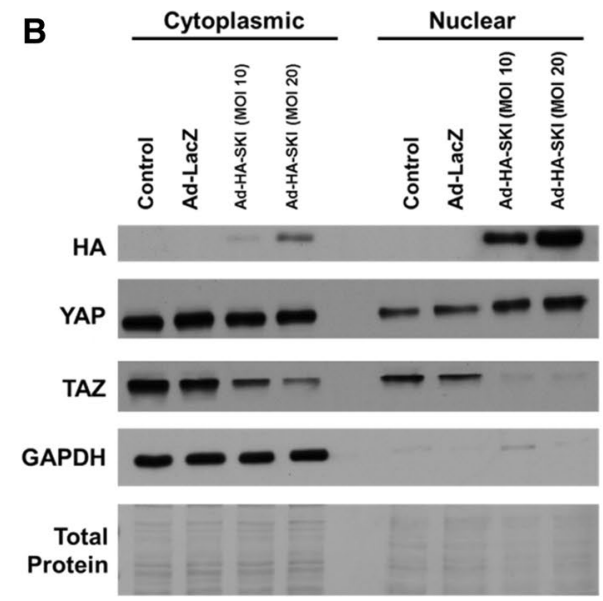

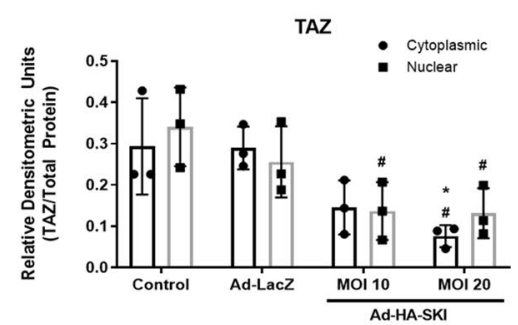

- Yap

$\triangle T$ Taz

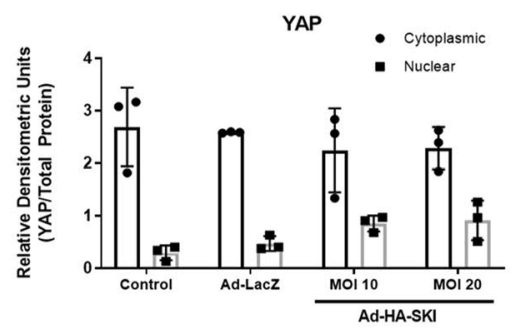

E

P1 + LATS1 SIRNA

P1 + LATS2 SIRNA

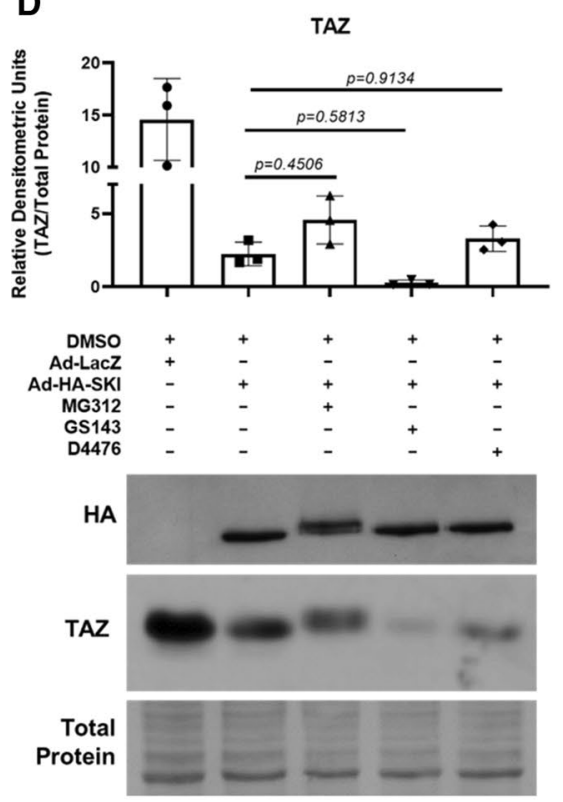

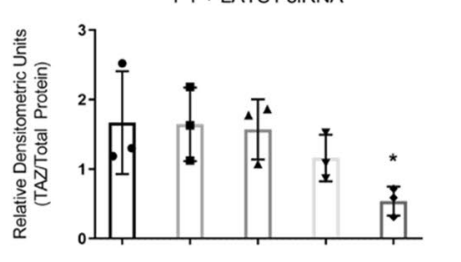

Non-Targeting siRNA

Ad-HA-Ski
LATS1 siRNA

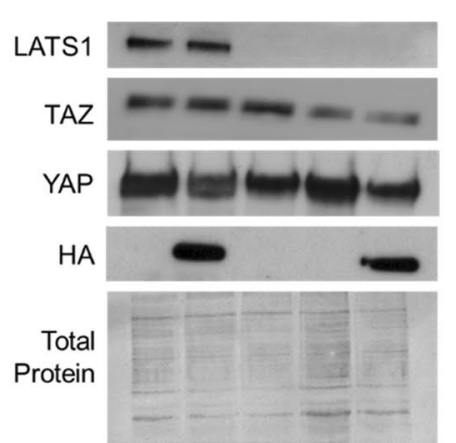

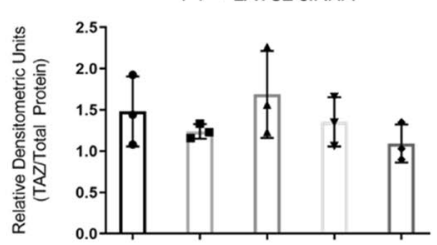

Ad-LacZ

Ad-HA-Ski

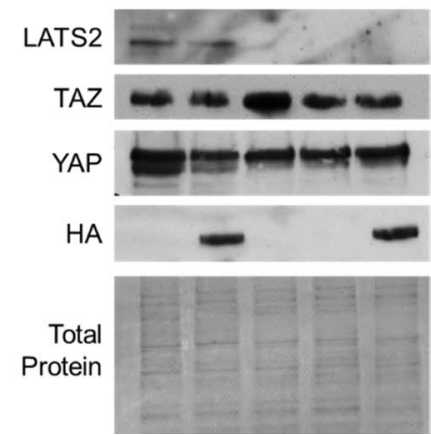


4Fig. 5 SKI induces proteasomal degradation of TAZ, but not YAP. First-passage (P1) primary rat cardiac myofibroblast were cultured on stiff plastic surfaces and infected with SKI overexpressing adenovirus (Ad-HA-SKI) at a low and high MOI (10 and 20, respectively) for $36 \mathrm{~h}$ prior to harvesting. a Whole cell lysates were probed by immunoblotting. Data are representative of $n=3$ biological replicates, where $* * P<0.01$ when compared to non-treated and Ad-LacZ infected controls. b Immunoblotting of nuclear and cytoplasmic subcellular fractions, showing an enrichment of nuclear-localized SKI. Data are representative of $n=3$ biological replicates, where $* P<0.05$ when compared to Ad-LacZ infected controls and ${ }^{\#} P<0.05$ when compared to untreated controls. c Gene expression was assayed by qRT-PCR, specifically targeting Yap and Taz, as well as their genetic target, Ctgf. Data are representative of $n=4$ biological replicates, where $* P<0.05$ when compared to Ad-LacZ infected controls for the given genetic target. d P1 rat cardiac fibroblasts were pre-treated with either MG132 $(1 \mu \mathrm{M})$, GS143 $(1 \mu \mathrm{M})$, or D4476 (500 nM) for $3 \mathrm{~h}$ prior to infection with either Ad-HA-SKI or Ad-LacZ control for $24 \mathrm{~h}$. Data are representative of $n=3$ biological replicates. e Prior to infection with SKI-expressing adenovirus, P1 rat cardiac myofibroblasts where transfected with siRNA targeting Lats1 and Lats2 kinases for $24 \mathrm{~h}$. Cells were subsequently harvested after $36 \mathrm{~h}$ of viral infection. Data are representative of $n=3$ biological replicates for each condition, where $* P<0.05$ compared to cells treated with nontargeting siRNA and Ad-LacZ. All data are displayed (A-E) as the mean \pm SD

also was associated with a loss of TAZ knockdown, and we attribute this to be experimental artifact. From this, we conclude that SKI regulates Hippo signaling in cardiac myofibroblasts by activating LATS2, and this de-repression may then allow for its kinase activity to specifically target TAZ for phosphorylation and degradation (Fig. 9). The apparent destabilizing of TAZ protein contributes to SKI's inhibition of the myofibroblast phenotype.

\section{SKI modulates actin cytoskeleton dynamics in cardiac myofibroblasts}

We previously showed that SKI downregulates myofibroblast markers in vitro [31]; however, it remains unknown as to whether SKI may influence the effects of the mechanotransduction on stiff substrate. This is salient, as the Hippo pathway is intimately linked to focal adhesions and the actin cytoskeleton, in that it is activated when the cell experiences less mechanical tension and there is a decrease in F-actin stress fibers [15]. Using primary rat cardiac myofibroblasts cultured on stiff substrates, we overexpressed SKI and compared $\mathrm{F}$ - and soluble free $\mathrm{G}$-actin ratios to those in Ad-LacZ infected controls. Using cytoskeletal subcellular fractionation and immunoblotting, it was found that SKI significantly reduces relative $\mathrm{F}$-actin levels, and increases free $\mathrm{G}$-actin, even in the presence of high mechanical tension (Fig. 6a). Similar results were observed in immunofluorescence assays, where rhodamine-phalloidin staining was greatly reduced in myofibroblasts overexpressing SKI (Fig. 6b). In addition, siRNA-mediated knockdown of endogenous $S k i$ yielded unremarkable results when P0 cardiac fibroblasts were cultured on stiff plastic substrates and treated with exogenous TGF- $\beta 1$ (Supplemental Fig. 4). However, when the knockdown was carried out on $5 \mathrm{kPa}$ compressible surfaces, there was nearly complete elimination of F-actin, as evidenced by the absence of phalloidin staining, when compared to non-targeting siRNA controls (Fig. 6c, d). Thus the Hippo pathway may be activated by a decrease in F-actin polymerization, and SKI is apparently required to mediate some processes which regulate the synthesis and breakdown of actin fibres. The results indicate that the absence of SKI on a soft matrix yields comparable results to the activation of SKI on a stiff matrix, and the pathophysiological implications likely point to a link between SKI dysregulation and matrix remodelling. These data, along with the evidence corroborating SKI's effects on Hippo pathway components, indicate that SKI promotes the cardiac fibroblast phenotype by a multifaceted antagonism of TAZ activity.

\section{The SKI and TAZ interactomes overlap in cardiac fibroblasts}

As SKI and TAZ are not known to be binding partners, and SKI's effects on the Hippo pathway remained elusive, we chose to perform BioID2 assays on both SKI and TAZ to elucidate whether SKI activates LATS2 in a direct or indirect manner. Using BioID2 fusion bait proteins expressed by adenoviral vectors, we captured the SKI and TAZ interactomes in primary human cardiac fibroblasts. We analyzed data from two biological replicates for each bait, and four controls consisting of untreated cell lysate to rule out endogenously biotinylated protein, as well as empty BioID2 to rule out proteins that may have a natural affinity for the BirA ligase.

The SKI interactome consisted of 32 potential interactors, while the TAZ interactome contained 53 (Fig. 7a). Previously published interactors for both SKI (e.g., NCoR1) and TAZ (e.g., TEAD3) were used to confirm the validity of experiments, and verified by Western blot (Fig. 7b, d). We interrogated both interactomes against each other and found several interactors in common, 3 of which are associated with actin cytoskeleton dynamics: Palladin (PALLD), WASH Complex Subunit 5 (WASHC5, formerly KIAA0196), and Capping Protein Regulator and Myosin 1 Linker 2 (CARMIL2, formerly RLTPR). Pathway analysis of the SKI interactome indicated modest pathway enrichment for Notch signaling, adipogenesis, and senescence and autophagy (Fig. 7c). The TAZ interactome was most enriched for gene transcription, Hippo signaling, and cellular responses to stress and external stimuli. Within the SKI interactome, two candidate interactors became of interest, because they are suspected to regulate the Hippo pathway: PJA2 ubiquitin ligase and 
A
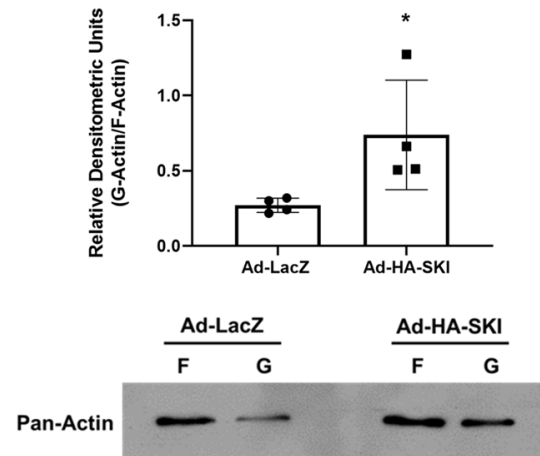

C

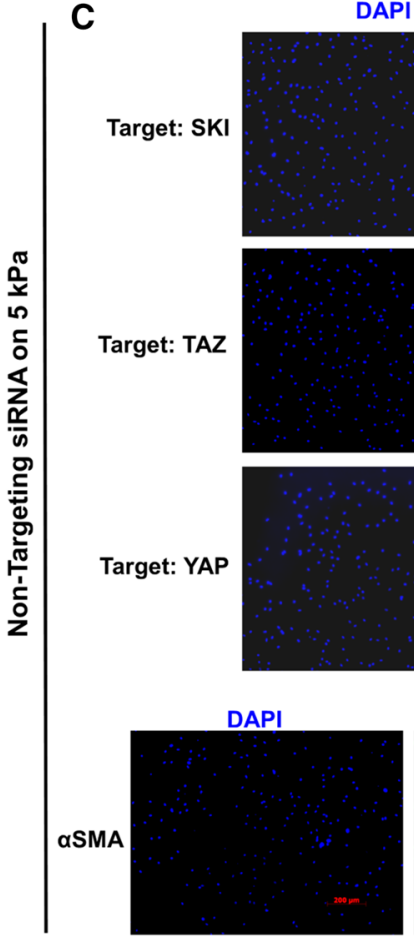

DAPI
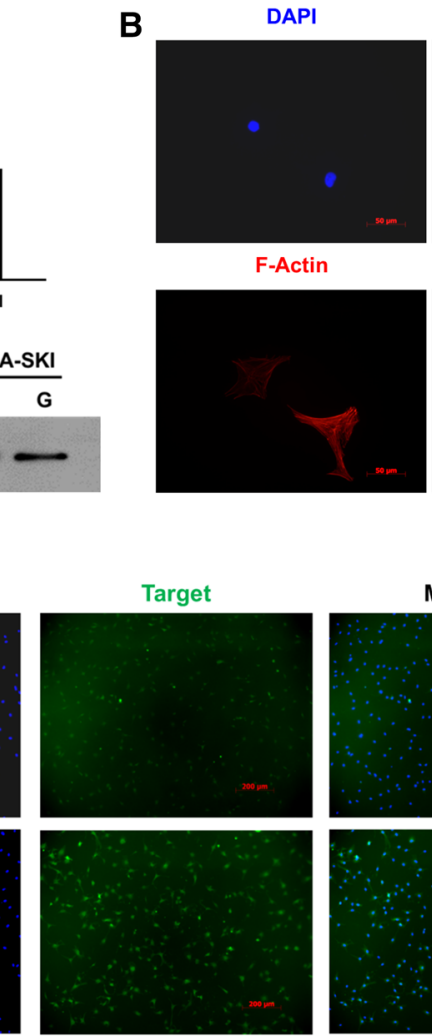

F-Actin
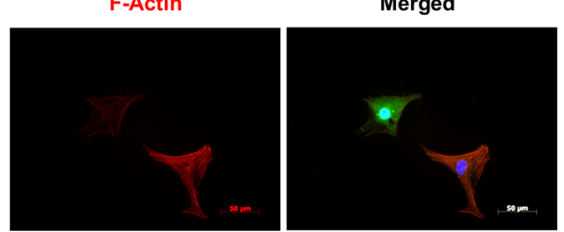

HA-SKI

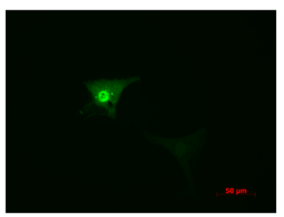

Merged

列 


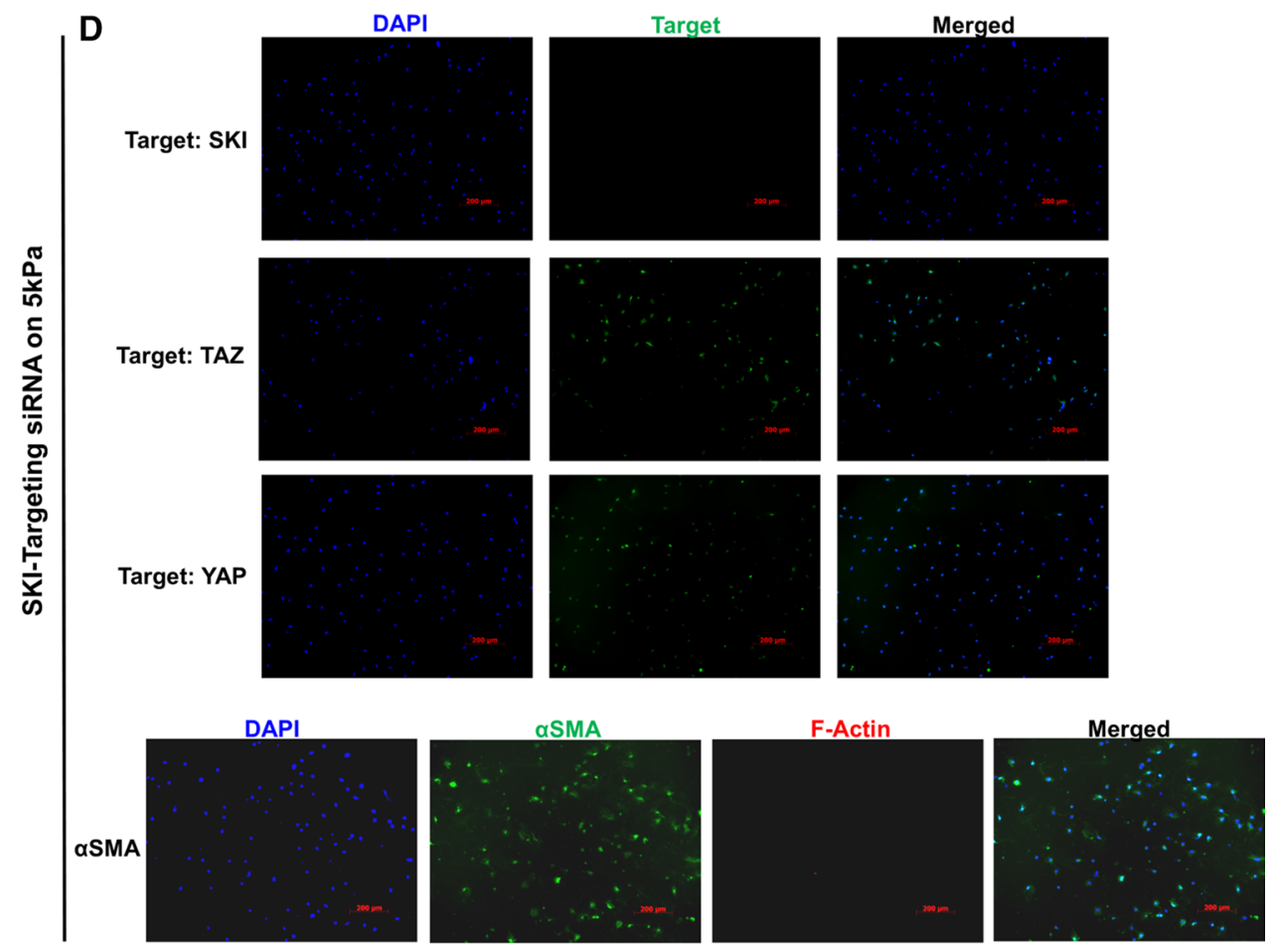

Fig. 6 (continued)

\section{LIMD1 mediates SKI's effects on TAZ}

LIMD1 has not been previously examined in the context of regulation of cardiac fibroblast activation. Therefore, we queried LIMD1 in primary rat cardiac myofibroblasts in vitro using both SKI overexpression and RNAi-mediated Limdl knockdown. The expression of LIMD1 protein in cardiac myofibroblasts was unaffected by neither AdLacZ, nor non-targeting siRNA pools (Fig. 8a, b). However, there was a notable decrease in endogenous LIMD1 expression with SKI overexpression, suggesting that whatever interaction exists between the two, it promotes the downregulation of LIMD1 protein expression. Limd1 knockdown mimicked SKI overexpression in that only TAZ was apparently affected by decreased LIMD1 expression, whereas YAP expression remained entirely unaltered. When probing for LIMD1 by immunofluorescence, there was a decrease of its the staining between SKI-overexpressing and Ad-LacZ infected controls (Fig. 8d), with a notable shift from cytosolic to nuclear expression. There was no overt co-staining of SKI and LIMD1 in the cytosol; however, the nucleus was positively stained for both proteins. Finally, when looking at mRNA transcription with SKI overexpression, there was no significant change in Limdl transcription (Fig. 8c), suggesting that SKI may indeed interact with LIMD1 protein to downregulate its function or activity in cardiac myofibroblasts.

\section{Discussion}

The activation of cardiac fibroblasts to hyper-secretory, hyper-proliferative myofibroblasts is a phenomenon wherein the subcellular mechanisms are still poorly understood. Initially triggered by the release of cytokines after myocardial injury (i.e., MI, hypertension, diabetes), cardiac fibroblast activation is the primary event necessary for physiological wound healing; however, its chronic stimulation promotes cardiac fibrosis and ultimately leads to heart failure. Here, we demonstrate that Hippo signaling is a modulator of cardiac fibroblast physiology and that it is positively regulated by SKI. SKI is a protein that is typically regarded solely as an inhibitor of SMAD-dependent TGF- $\beta$ signaling. Our findings suggest that SKI interacts with-and likely inhibits-LIMD1, which then de-represses the LATS2 kinase; this, in turn, enables LATS2 to specifically phosphorylate and cause the proteasomal degradation of TAZ (Fig. 9). Furthermore, we found that LATS2 interacts with TAZ whereas LATS1 does not (Fig. 7), and that LATS2 knockdown prevented TAZ downregulation with SKI overexpression (Fig. 5e). The signaling cascade results in a decrease in myofibroblast markers, and promotion of the quiescent fibroblast phenotype.

Our prior studies demonstrate that SKI is dysregulated (i.e., sequestered to the cytosol), during post-MI cardiac remodeling and fibrosis and functions to downregulate the 
A

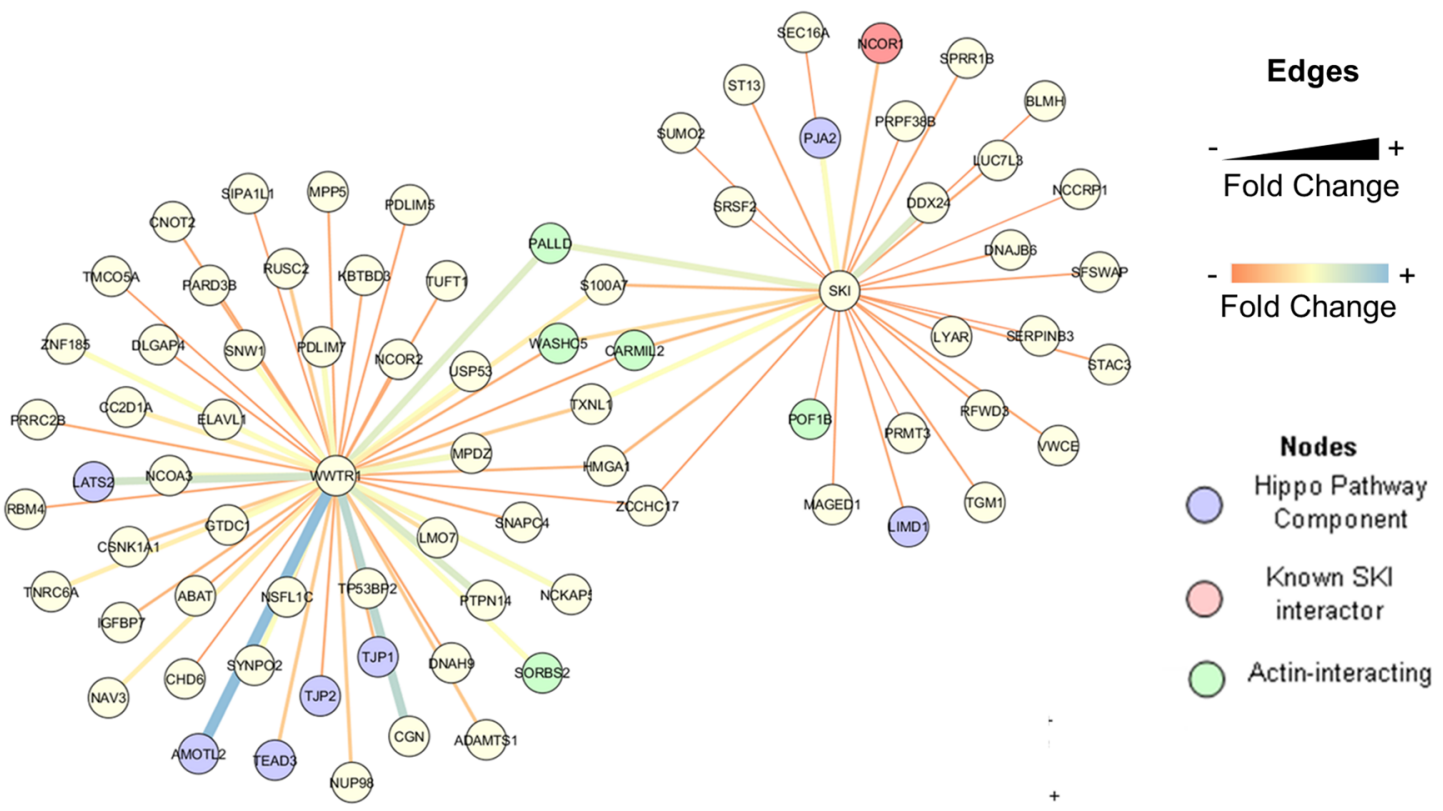

B
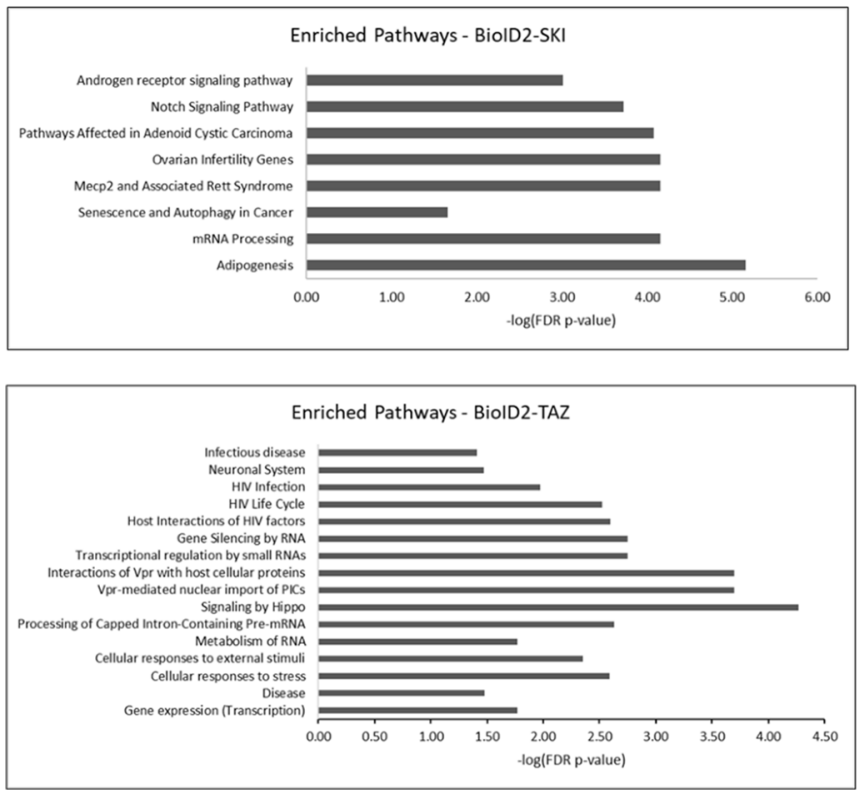

C

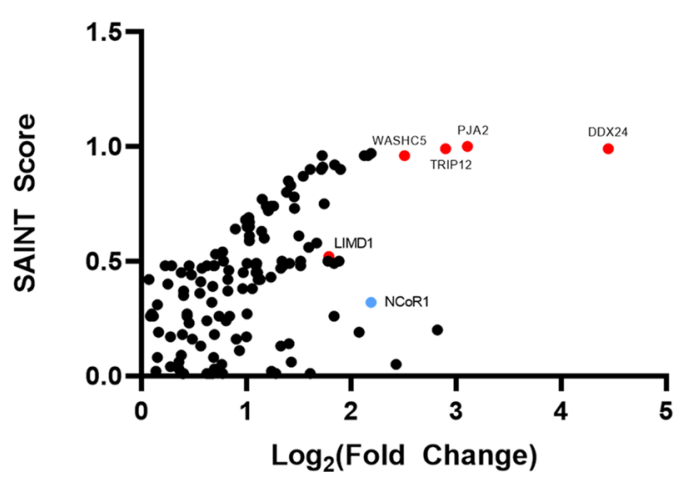

D

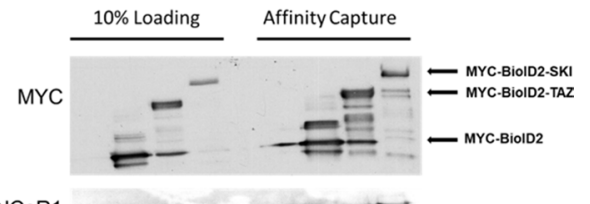

NCoR1

LIMD1 - - - -

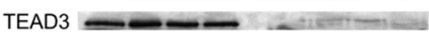

Ad-BiolD-Empty

Ad-BiolD-TAZ

Ad-BiolD-SKI

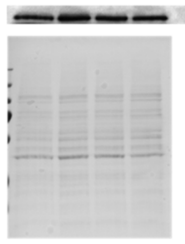

$-+-$

$-+-$

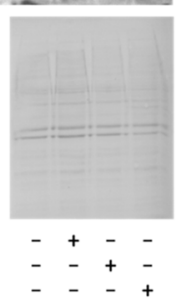

BiolD2-TAZ

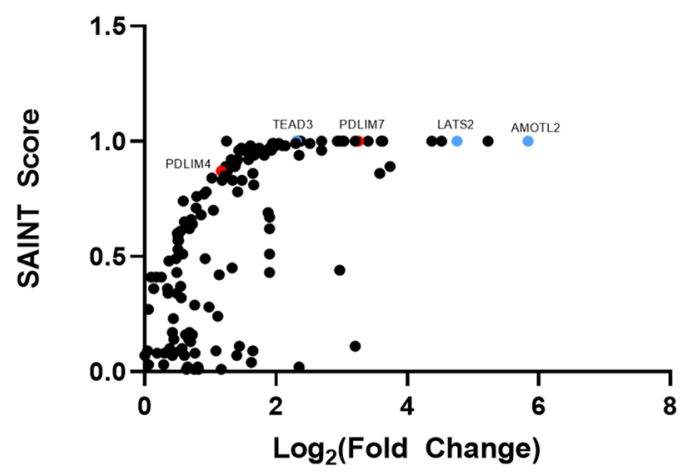


४Fig. 7 SKI and TAZ interactomes overlap in primary human cardiac fibroblasts. Primary human cardiac fibroblasts were infected with adenovirus constructs overexpressing MYC-BioID2 fusion proteins (TAZ or SKI) or empty MYC-BioID2 for $24 \mathrm{~h}$. Cell cultures were then supplemented with $20 \mu \mathrm{M}$ biotin, and incubated for another $24 \mathrm{~h}$ prior to harvesting. Untreated controls were also included to exclude endogenously biotinylated proteins. a Graphical representation of the TAZ (WWTR1) and SKI interactomes in human cardiac fibroblasts. Edge thickness and color is representative of the fold-change enrichment of the prey obtained by affinity capture. Hippo pathway components are highlighted in violet, while known SKI interactors are highlighted in red. b Pathway enrichment analysis for both SKI and TAZ interactomes. c Plotting of SAINT scores versus $\log 2$ foldchange enrichment of potential interactors. A SAINT score closer to 1 indicates greater likelihood of interaction. Select known interactors are indicated in blue, while novel interactors are indicated in red. d Immunoblotting was used to confirm novel interaction between SKI and LIMD1. Data shown are representative of $n=4$ biological replicates

expression of $\alpha$ SMA and ED-An FN $[11,12]$ in primary cardiac myofibroblasts. It was also established that SKI overexpression in primary cardiac myofibroblasts upregulates MMP-9 transcription and secretion [31], and its chronic expression represses autophagy-mediated survival responses which normally enable the pro-fibrotic phenotype to persist [60]. Recently it was found that SKI functions to inhibit pro-fibrotic signaling in cardiac myofibroblasts via SMADindependent MAPK signaling [61], suggesting that its functions are far more pleiotropic than initially described. We demonstrate for the first time that SKI activates Hippo signaling in cardiac myofibroblasts and does so in a manner than only targets TAZ, and not YAP. We have also observed that TAZ expression is significantly upregulated in the expanding infarct scar during chronic post-MI remodeling, while increased YAP expression is distinctly observable in the vasculature; this is a compelling observation as YAP and TAZ are often described as having the same or redundant functions in a given pathology. We suggest that while YAP does possess some pro-fibrotic properties and is the more routinely examined effector of the Hippo pathway, TAZ is possibly more closely implicated in cardiac fibroblast activation and post-MI fibrosis. Our Western data indicate coincident expression of TAZ and POSTN in both viable (surviving) left ventricular myocardium and in the infarct scar of postMI rat hearts, and accompanying immunofluorescence studies shows some scattered TAZ expression in post-MI hearts is localized to the infarct scar, with relatively intense staining in medial layer of the vasculature in the myocardium adjacent to the infarct scar and in the cardiomyocytes of the border zone surviving myocardium (Fig. 4b, and Supplemental Fig. 5). Thus the increase in TAZ observed in these tissues may be a combination of myofibroblast expression, activated vascular smooth muscle and surviving cardiomyocytes in the myocardium bordering the infarct scar.
Recent investigations have addressed the role of the Hippo pathway in the context of post-MI cardiac fibrosis. Using $T c f 21^{\text {MerCreMer }}$-Lats $1 / 2^{\mathrm{f} / \mathrm{fl}}$ model, Xiao et al. demonstrated that not only did fibroblast-specific deletion of both the LATS kinases yielded spontaneous myocardial fibrosis, but also exacerbated the severity of post-MI scar formation [56]. Although the study also included an examination of the post-MI response in $T c f 21^{\text {MerCreMer }}$-Lats $1 / 2^{\mathrm{f} / / \mathrm{f}}-{ }_{-}{ }^{\mathrm{f}} \mathrm{p}^{\mathrm{f} / \mathrm{fl}}$ mice as well, it is unclear whether the combined deletion of Lats1, Lats2, and Yap in cardiac fibroblasts markedly reduced the degree to which replacement fibrosis expanded compared to controls. In addition, RNAseq and chromatin occupancy studies indicated that in the absence of LATS1/2, YAP activation promotes a shift in ECM-related gene expression, and upregulates the proto-oncogene c-MYC. While these findings are valuable to understanding YAP activation, the data were acquired in immortalized NIH-3T3 fibroblasts, rather than in primary cells [56]. Despite these findings, there are no data in the literature regarding the expression of TAZ in concert with Lats 1/2 deletion, an experiment which would once again clarify whether YAP and TAZ are indeed redundant or independent in the context of cardiac fibrosis. It would be of interest to determine whether the observed paradigm also exists within activated myofibroblasts, as the model employed the $T c f 21$ promoter, known only to be active in the quiescent fibroblast phenotype [26, 51].

While it has been argued that TAZ plays a redundant role in cardiomyocyte survival and proliferation with respect to YAP [55], we postulate that TAZ may target and upregulate a unique pro-fibrotic gene program during post-MI wound healing. Studies in other fibrotic pathologies have previously reported disparate expression patterns between YAP and TAZ, suggesting that these paralogs should not always be considered functionally linked. For example, work by Liu et al. to investigate idiopathic pulmonary fibrosis (IPF) indicate that TAZ upregulation exceeds that of YAP in IPF tissue, as its expression is predominantly nuclear in activated fibroblasts within diseased samples [35]. Similar results have been confirmed by other groups [39], and are echoed in studies of chronic kidney disease and renal fibrosis $[1,38]$. Our data are in agreement with these findings, but also implicate SKI in the specific regulation of TAZ in the context of tissue fibrosis. As the current literature is primarily focused on YAP as the main nuclear Hippo pathway effector, and tendency to refer to YAP and TAZ interchangeably, it will be of benefit for future investigators to use a design which includes independent examination of these paralogs as separate entities with unique, and likely cell-specific functions. The evidence presented in the current study was obtained using constitutively active variants of YAP and TAZ, which yielded similar results for both paralogs in overexpression studies and thus the likelihood for the existence of further intracellular, extracellular, and matrix-mediated signaling 
A

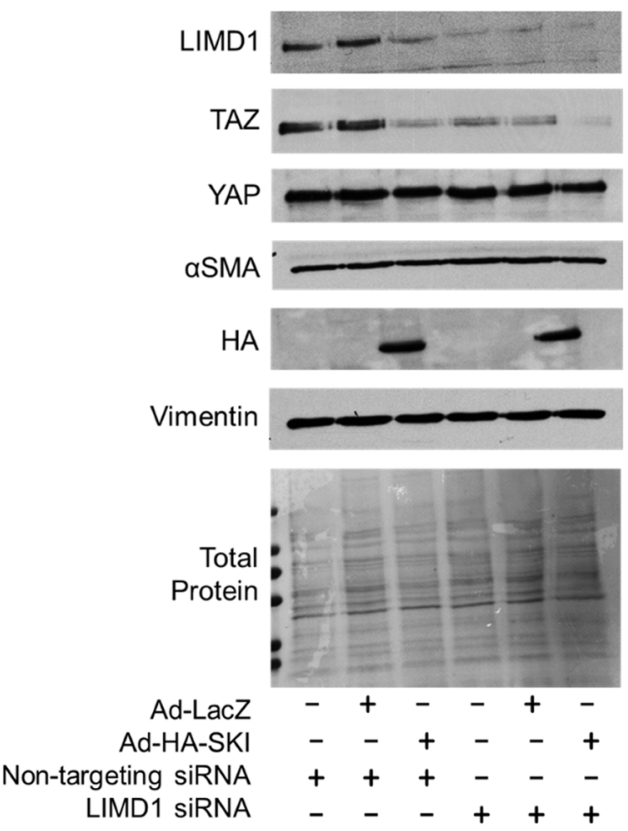

C

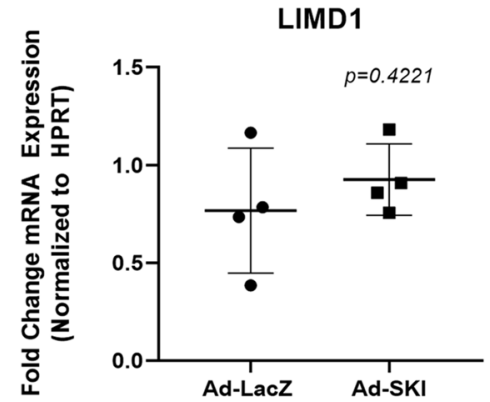

D
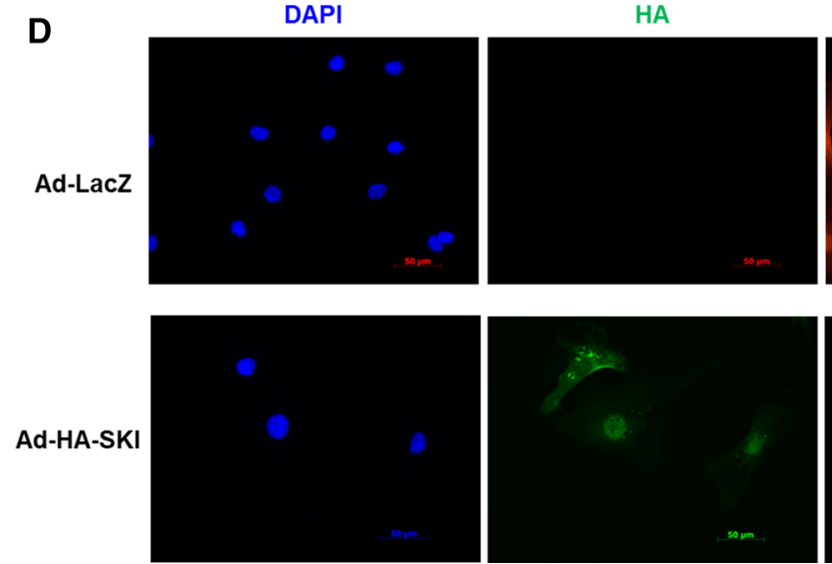

B

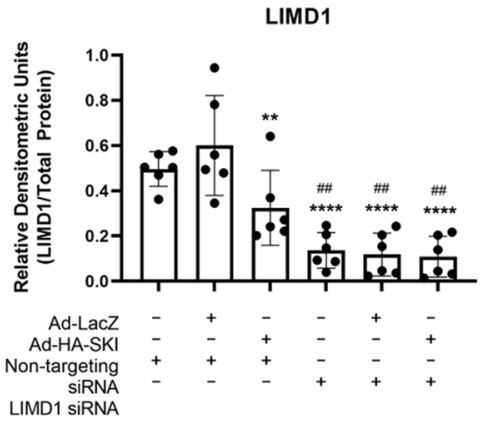

TAZ

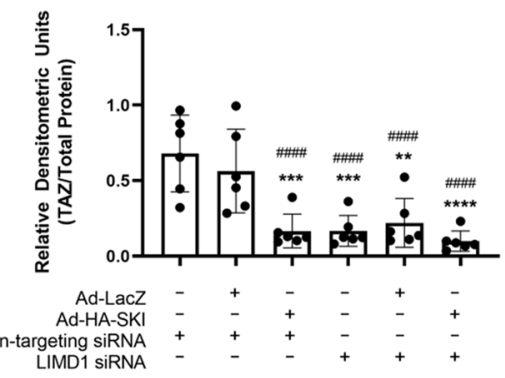

YAP

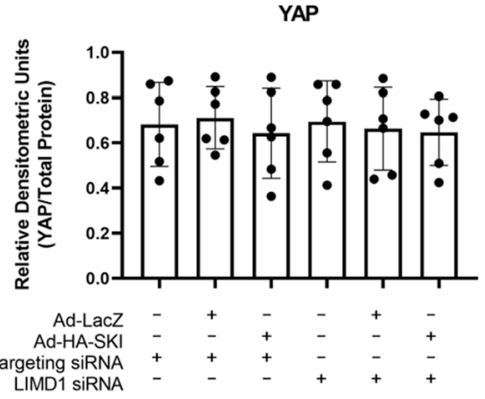

LIMD1
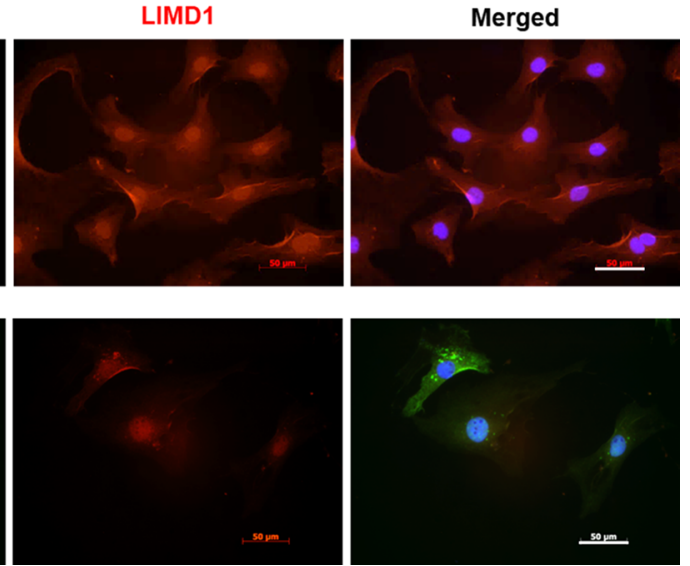

Fig. 8 TAZ expression is regulated by LIMD1 in cardiac myofibroblasts. a Immunoblotting of whole cell lysates from activated (P1) primary rat cardiac myofibroblasts transfected with siRNA targeting Limdl $24 \mathrm{~h}$ prior to infection with Ad-HA-SKI or Ad-LacZ control. A non-targeting siRNA pool functioned as a control. b Quantification of data shown in A, with $n=6$ biological replicates. ${ }^{*} P<0.01$, $* * * * \mathrm{P}<0.001$ when compared to Ad-LacZ infected controls; \#\# $P<0.01$, \#\#\#P<0.001, \#\#\#\#P<0.0001 when compared to cells only treated with non-targeting siRNA pool. c, d P1 primary rat car- diac myofibroblasts were cultured on stiff plastic (C) or glass (D) surfaces and infected with SKI-expressing adenovirus (Ad-HA-SKI) for $36 \mathrm{~h}$. mRNA was isolated and (C) qRT-PCR of Limdl was performed on $n=4$ biological replicates. Fixed cells (D) were probed for LIMD1 (red) and HA-SKI (green) by indirect immunofluorescence, with nuclei counterstained with DAPI (blue). Scale bar $=50 \mu \mathrm{m}$. Images are representative of $n=3$ biological replicates, with 2 technical replicates each. Data shown in B and C are reported as the mean \pm SD 
Fig. 9 Model of SKI-mediated regulation of Hippo signaling and cardiac fibroblast activation. When SKI is localized in the cytoplasm, LIMD1 can freely associate and inhibit the function of LATS2 kinase, thus allowing TAZ-dependent, pro-fibrotic signaling to occur. Conversely, when SKI is functioning in the nucleus, it inhibits LIMD1 which, in turn, de-represses LATS2 kinase. The result is the phosphorylation and proteasomal degradation of TAZ, and the inhibition of the activated myofibroblast phenotype

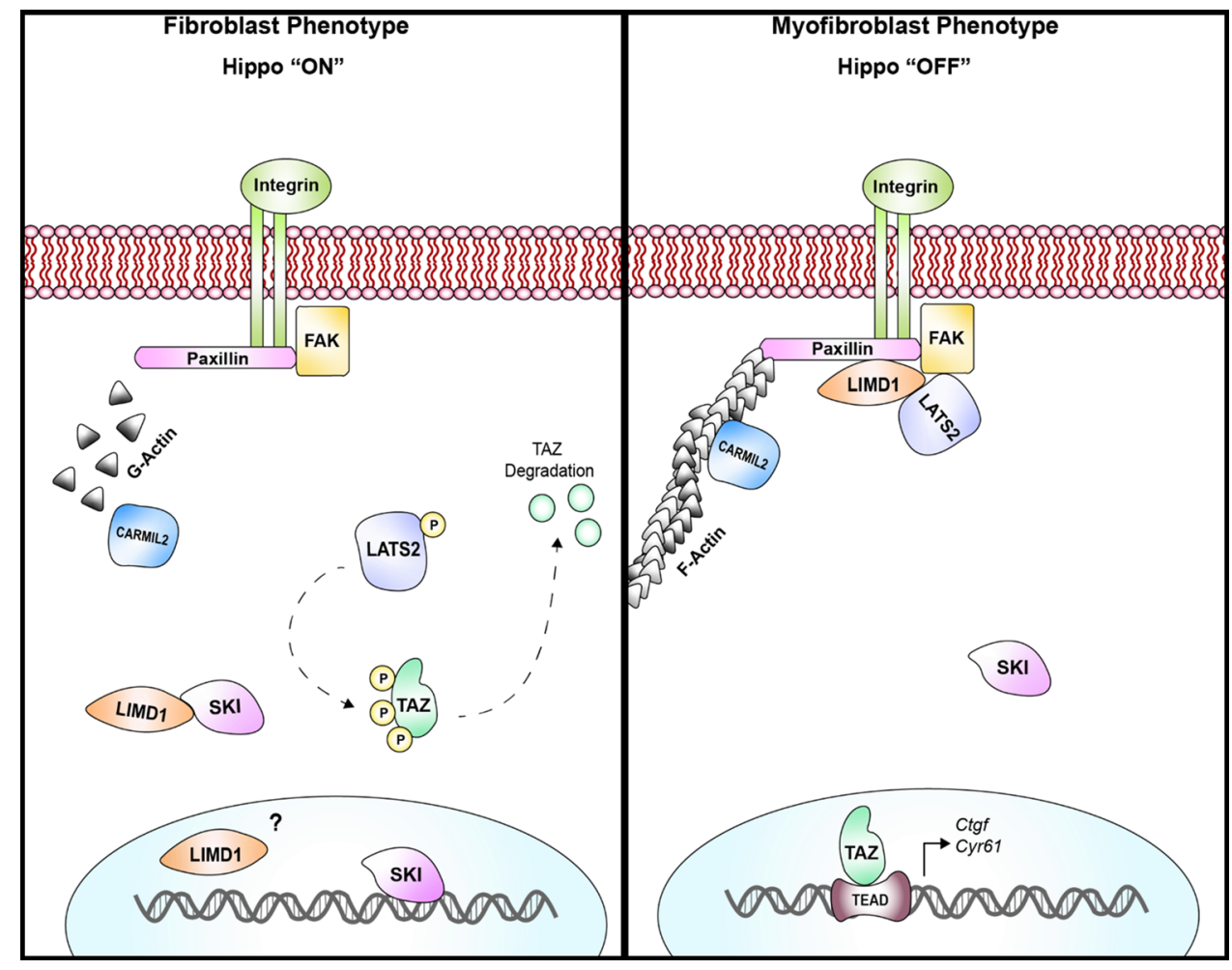

to promote or deter YAP/TAZ activation in cardiac fibrosis is high.

We carried out BioID2 analyses to address novel mechanisms by which SKI interacts, and potentially regulates, Hippo signaling in primary cardiac fibroblasts. Previous oncological studies suggest that SKI interacts with several core Hippo pathway components, including LATS2; however, they utilized cancer cell lines (i.e., breast, kidney, and lung) $[40,58]$. They revealed a decrease in TAZ protein expression with ectopic SKI expression, as well as a marked reduction in cell proliferation, migration, and tumorigenicity. The work done by Rashidian et al. suggests that SKI directly interacts with several components of the Hippo pathway (e.g., LATS2, MOB1, MOB2) [40]. We point out that these results were obtained outside the context of genuine pathology, as they were conducted in HEK $293 \mathrm{~T}$ cells overexpressing both the bait and prey proteins. Several other groups have remarked that physiological SKI functionality is not observable in most cell lines, and therefore, those studies should be cautiously interpreted [5, 6, 48, 52]. Several reports indicate that SKI's functions are often both cell- and pathology-specific (as reviewed by Tecalco-Cruz and colleagues [52]), and this is especially evident when examining results from immortalized cells. To first demonstrate the efficacy of the BioID2 system, we captured the interactome of both SKI in HEK 293A cells, and found that the hits acquired from the test largely corroborated the literature (Supplemental Fig. 2a). However, when comparing this SKI interactome to that captured from primary human cardiac fibroblasts, only three interactors overlap among them (Supplemental Fig. 2b). With respect to the cardiac fibroblast SKI interactome, we specifically focused on LIMD1 as a point of interaction between SKI and Hippo signaling as it had already been implicated in the modulation of LATS-dependent Hippo inhibition. Additionally, when considering the TAZ cardiac fibroblast interactome, several LIM domain proteins were identified as potential points of interaction (Fig. 6A), including PDLIM5, suggesting that there may be another measure of TAZ regulation that has yet to be described.

While several LIM domain protein family members have been identified, their role in cell physiology and pathophysiology remains largely unknown. There is some evidence that LIMD1 functions as a scaffold for protein-protein interactions [16], and may play a role in cytoskeletal organization [2]. LIMD1 has been reported to inhibit the activity of LATS kinases by sequestering them to the cytosol and at focal adhesions and junctional complexes [21, 23]. Work by Jagannathan et al. also demonstrated that LIMD1 modulated YAP activity in proliferating epithelial cells, and that this regulatory process functions independently of substrate or ECM stiffness [23]. This notwithstanding, the majority of these studies were conducted in cell lines, and may not accurately reflect physiologic LIMD1 regulation. We observed a decrease in LIMD1 expression upon induction of SKI in vitro (Fig. 8B), which coincides with a decrease 
in actin polymerization and stress fiber formation. Previous studies in other mesenchymal cells have shown that LIMD1 expression is reduced by treatment with the myosin-II inhibitor, blebbistatin [20, 43]. It is possible that SKI's effects on the actin cytoskeleton may be more direct in generating the downregulation of LIMD1. Other studies in PDZ-LIM proteins have demonstrated that their association with the CARMIL2 (formerly Arp2/3) actin-nucleating protein dictates stress fiber cross-linking [36]. This is of note as we isolated CARMIL2 as a potential SKI interactor in the BioID2 assay. SKI's interaction or inhibition of LIMD1 may be in a complex with CARMIL2, although this has yet to be confirmed. Despite the current lack of evidence directly linking TAZ and LIMD1, our findings indicate that LIMD1 is a key inhibitor of the TAZ-Hippo pathway in cardiac fibroblasts, and that its absence yields a similar cellular response as does SKI overexpression.

\section{Conclusions}

SKI is an anti-fibrotic protein whose function(s) may extend beyond canonical TGF- $\beta 1$ signaling. We elucidate novel molecular mechanisms governing cardiac fibroblast phenotype modulation, and these findings warrant further investigation of Hippo signaling and its therapeutic targeting within the context of cardiac fibrosis. Our current results improve our understanding of the role of TAZ and YAP as stand-alone, distinct factors in fibrogenesis. The data also present a novel mechanism of action for SKI, which is intimately linked to the actin cytoskeleton. Future studies to examine LIMD1 and its function in cardiac fibroblasts in combination with SKI's role in fibroblast physiology may lead to the generation of data that could be exploited for selective therapeutic targeting in cardiac fibrosis and heart failure.

Supplementary Information The online version contains supplementary material available at https://doi.org/10.1007/s00395-021-00865-9.

Acknowledgements Many thanks to Dr. Mark Hnatowich, for his assistance with vector design and sequencing. We are grateful to Dr. John Wilkins, Ms. Ying "Tenny" Lao, and the Manitoba Centre for Proteomics and Systems Biology for their assistance with mass spectrometry experiments. We are also indebted to the staff of the R.O. Burrell Surgical Education and Research Facility (Albrechtsen Research Centre); especially to Sheri Bage for her technical expertise. Many thanks are also extended to Drs. Randolph Faustino (Sanford Institute, Sioux Falls, SD) and Barbara Triggs-Raine (University of Manitoba) for their advice.

Author contributions NML contributed to the study conceptualization, methodology, validation, investigation, analysis, data curation, writing (draft, review, editing, revisions), and visualization. SGR was integral to the conceptualization, methodology, investigation, data curation, writing (review, editing, revisions), and project administration. KLF,
CFM, TWM, SCM, and SJF contributed by performing investigations, revisions, and assisted in data curation. NK and RRF assisted with methodology, investigation, writing (review, editing). EK and TAD were responsible for funding acquisition, procuring resources, writing (review, editing, revisions), and general supervision. IMCD oversaw the entire study and was central to the conceptualization of experiments, project administration, funding acquisition, and writing of the manuscript (review, editing and all revisions).

Funding Operating support for this work was provided by grants from the Canadian Institutes of Health Research (CIHR - IMCD PJT-162163 and EK MOP-74733) and the Heart \& Stroke Foundation of Canada (IMCD, G-17-0018631). This work was also funded by studentships from the CIHR (NML), Research Manitoba (NML and KLF), and Bank of Montreal scholarships (NML and NK).

Availability of data and materials The data sets used and/or analyzed during the current study are available from the corresponding author on reasonable request. The mass spectrometry data are available as part of the online data supplement, as well as on the ProteomeXchange PRIDE partner repository, as described in the methods section.

\section{Declarations}

Competing interests The authors declare that they have no competing interests.

Ethics approval and consent to participate All studies presented herein were conducted in accordance with the guidelines and principles of the Canadian Council on Animal Care (CCAC), as well as the Canadian Tri-Council Policy Statement for Ethical Conduct on Research Involving Humans (TCPS 2, 2018). Complete information regarding ethics approvals is provided in the methods section.

Consent for publication Not applicable.

Open Access This article is licensed under a Creative Commons Attribution 4.0 International License, which permits use, sharing, adaptation, distribution and reproduction in any medium or format, as long as you give appropriate credit to the original author(s) and the source, provide a link to the Creative Commons licence, and indicate if changes were made. The images or other third party material in this article are included in the article's Creative Commons licence, unless indicated otherwise in a credit line to the material. If material is not included in the article's Creative Commons licence and your intended use is not permitted by statutory regulation or exceeds the permitted use, you will need to obtain permission directly from the copyright holder. To view a copy of this licence, visit http://creativecommons.org/licenses/by/4.0/.

\section{References}

1. Anorga S, Overstreet JM, Falke LL, Tang J, Goldschmeding RG, Higgins PJ, Samarakoon R (2018) Deregulation of Hippo-TAZ pathway during renal injury confers a fibrotic maladaptive phenotype. FASEB J 32:2644-2657. https://doi.org/10.1096/fj.20170 0722R

2. Bai SW, Herrera-Abreu MT, Rohn JL, Racine V, Tajadura V, Suryavanshi N, Bechtel S, Wiemann S, Baum B, Ridley AJ (2011) Identification and characterization of a set of conserved and new regulators of cytoskeletal organization, cell morphology 
and migration. BMC Biol 9:54. https://doi.org/10.1186/ 1741-7007-9-54

3. Bertero T, Cottrill KA, Lu Y, Haeger CM, Dieffenbach P, Annis S, Hale A, Bhat B, Kaimal V, Zhang YY, Graham BB, Kumar R, Saggar R, Saggar R, Wallace WD, Ross DJ, Black SM, Fratz S, Fineman JR, Vargas SO, Haley KJ, Waxman AB, Chau BN, Fredenburgh LE, Chan SY (2015) Matrix Remodeling Promotes Pulmonary Hypertension through Feedback Mechanoactivation of the YAP/TAZ-miR-130/301 Circuit. Cell Rep 13:1016-1032. https://doi.org/10.1016/j.celrep.2015.09.049

4. Bhandary B, Meng Q, James J, Osinska H, Gulick J, ValienteAlandi I, Sargent MA, Bhuiyan MS, Blaxall BC, Molkentin JD, Robbins J (2018) Cardiac fibrosis in proteotoxic cardiac disease is dependent upon myofibroblast TGF -beta signaling. JAHA 7:e010013. https://doi.org/10.1161/JAHA.118.010013

5. Bonnon C, Atanasoski S (2012) c-Ski in health and disease. Cell Tissue Res 347:51-64. https://doi.org/10.1007/ s00441-011-1180-z

6. Caligaris C, Vazquez-Victorio G, Sosa-Garrocho M, RiosLopez DG, Marin-Hernandez A, Macias-Silva M (2015) Actincytoskeleton polymerization differentially controls the stability of Ski and SnoN co-repressors in normal but not in transformed hepatocytes. Biochim Biophys Acta 1850:1832-1841. https:// doi.org/10.1016/j.bbagen.2015.05.012

7. Chaganti RS, Balazs I, Jhanwar SC, Murty VV, Koduru PR, Grzeschik KH, Stavnezer E (1986) The cellular homologue of the transforming gene of SKV avian retrovirus maps to human chromosome region 1q22-q24. Cytogenet Cell Genet 43:181186. https://doi.org/10.1159/000132318

8. Chan SW, Lim CJ, Chong YF, Pobbati AV, Huang C, Hong W (2011) Hippo pathway-independent restriction of TAZ and YAP by angiomotin. J Biol Chem 286:7018-7026. https://doi.org/10. 1074/jbc.C110.212621

9. Chen HI, Sudol M (1995) The WW domain of Yes-associated protein binds a proline-rich ligand that differs from the consensus established for Src homology 3-binding modules. Proc Natl Acad Sci U S A 92:7819-7823. https://doi.org/10.1073/pnas.92. 17.7819

10. Chen W, Lam SS, Srinath H, Schiffer CA, Royer WE Jr, Lin K (2007) Competition between Ski and CREB-binding protein for binding to Smad proteins in transforming growth factor-beta signaling. J Biol Chem 282:11365-11376. https://doi.org/10.1074/jbc. M700186200

11. Cunnington RH, Northcott JM, Ghavami S, Filomeno KL, Jahan F, Kavosh MS, Davies JJ, Wigle JT, Dixon IM (2014) The SkiZeb2-Meox2 pathway provides a novel mechanism for regulation of the cardiac myofibroblast phenotype. J Cell Sci 127:40-49. https://doi.org/10.1242/jcs.126722

12. Cunnington RH, Wang B, Ghavami S, Bathe KL, Rattan SG, Dixon IM (2011) Antifibrotic properties of c-Ski and its regulation of cardiac myofibroblast phenotype and contractility. Am J Physiol Cell Physiol 300:C176-186. https://doi.org/10.1152/ajpce 11.00050 .2010

13. Dieffenbach PB, Haeger CM, Coronata AMF, Choi KM, Varelas X, Tschumperlin DJ, Fredenburgh LE (2017) Arterial stiffness induces remodeling phenotypes in pulmonary artery smooth muscle cells via YAP/TAZ-mediated repression of cyclooxygenase-2. Am J Physiol Lung Cell Mol Physiol 313:L628-L647. https://doi. org/10.1152/ajplung.00173.2017

14. Dixon IM, Lee SL, Dhalla NS (1990) Nitrendipine binding in congestive heart failure due to myocardial infarction. Circ Res 66:782-788. https://doi.org/10.1161/01.res.66.3.782

15. Dobrokhotov O, Samsonov M, Sokabe M, Hirata H (2018) Mechanoregulation and pathology of YAP/TAZ via Hippo and non-Hippo mechanisms. Clin Transl Med 7:23. https://doi.org/ 10.1186/s40169-018-0202-9
16. Foxler DE, Bridge KS, James V, Webb TM, Mee M, Wong SC, Feng Y, Constantin-Teodosiu D, Petursdottir TE, Bjornsson J, Ingvarsson S, Ratcliffe PJ, Longmore GD, Sharp TV (2012) The LIMD1 protein bridges an association between the prolyl hydroxylases and VHL to repress HIF-1 activity. Nat Cell Biol 14:201-208. https://doi.org/10.1038/ncb2424

17. Fu X, Khalil H, Kanisicak O, Boyer JG, Vagnozzi RJ, Maliken BD, Sargent MA, Prasad V, Valiente-Alandi I, Blaxall BC, Molkentin JD (2018) Specialized fibroblast differentiated states underlie scar formation in the infarcted mouse heart. J Clin Invest 128:2127-2143. https://doi.org/10.1172/JCI98215

18. Ghosh AK, Quaggin SE, Vaughan DE (2013) Molecular basis of organ fibrosis: potential therapeutic approaches. Exp Biol Med (Maywood) 238:461-481. https://doi.org/10.1177/1535370213 489441

19. Huang J, Wu S, Barrera J, Matthews K, Pan D (2005) The Hippo signaling pathway coordinately regulates cell proliferation and apoptosis by inactivating Yorkie, the Drosophila Homolog of YAP. Cell 122:421-434. https://doi.org/10.1016/j.cell.2005.06. 007

20. Ibar C, Kirichenko E, Keepers B, Enners E, Fleisch K, Irvine KD (2018) Tension-dependent regulation of mammalian Hippo signaling through LIMD1. J Cell Sci. https://doi.org/10.1242/jcs. 214700

21. Ibar C, Kirichenko E, Keepers B, Enners E, Fleisch K, Irvine KD (2018) Tension-dependent regulation of mammalian Hippo signaling through LIMD1. J Cell Sci 131: pii: jcs214700 doi: https:// doi.org/10.1242/jcs.214700.

22. Ikeda S, Sadoshima J (2016) Regulation of myocardial cell growth and death by the hippo pathway. Circ J 80:1511-1519. https://doi. org/10.1253/circj.CJ-16-0476

23. Jagannathan R, Schimizzi GV, Zhang K, Loza AJ, Yabuta N, Nojima H, Longmore GD (2016) AJUBA LIM proteins limit hippo activity in proliferating cells by sequestering the hippo core kinase complex in the cytosol. Mol Cell Biol 36:2526-2542. https://doi.org/10.1128/MCB.00136-16

24. Kaan HYK, Chan SW, Tan SKJ, Guo F, Lim CJ, Hong W, Song H (2017) Crystal structure of TAZ-TEAD complex reveals a distinct interaction mode from that of YAP-TEAD complex. Sci Rep 7:2035. https://doi.org/10.1038/s41598-017-02219-9

25. Kanai F, Marignani PA, Sarbassova D, Yagi R, Hall RA, Donowitz M, Hisaminato A, Fujiwara T, Ito Y, Cantley LC, Yaffe MB (2000) TAZ: a novel transcriptional co-activator regulated by interactions with $14-3-3$ and PDZ domain proteins. EMBO J 19:6778-6791. https://doi.org/10.1093/emboj/19.24.6778

26. Kanisicak O, Khalil H, Ivey MJ, Karch J, Maliken BD, Correll RN, Brody MJ, SC JL, Aronow BJ, Tallquist MD, Molkentin JD, (2016) Genetic lineage tracing defines myofibroblast origin and function in the injured heart. Nat Commun 7:12260. https://doi. org/10.1038/ncomms12260

27. Karsdal MA, Nielsen SH, Leeming DJ, Langholm LL, Nielsen MJ, Manon-Jensen T, Siebuhr A, Gudmann NS, Ronnow S, Sand JM, Daniels SJ, Mortensen JH, Schuppan D (2017) The good and the bad collagens of fibrosis - Their role in signaling and organ function. Adv Drug Deliv Rev 121:43-56. https://doi.org/ 10.1016/j.addr.2017.07.014

28. Kelder T, Pico AR, Hanspers K, van Iersel MP, Evelo C, Conklin BR (2009) Mining biological pathways using WikiPathways web services. PLoS ONE 4:e6447. https://doi.org/10.1371/journal. pone. 0006447

29. Klingberg F, Chau G, Walraven M, Boo S, Koehler A, Chow ML, Olsen AL, Im M, Lodyga M, Wells RG, White ES, Hinz B (2018) The fibronectin ED-A domain enhances recruitment of latent TGF-beta-binding protein-1 to the fibroblast matrix. J Cell Sci. https://doi.org/10.1242/jcs.201293 
30. Kong P, Christia P, Frangogiannis NG (2014) The pathogenesis of cardiac fibrosis. Cell Mol Life Sci 71:549-574. https://doi.org/ 10.1007/s00018-013-1349-6

31. Landry N, Kavosh MS, Filomeno KL, Rattan SG, Czubryt MP, Dixon IMC (2018) Ski drives an acute increase in MMP-9 gene expression and release in primary cardiac myofibroblasts. Physiol Rep 6:e13897. https://doi.org/10.14814/phy2.13897

32. Landry NM, Rattan SG, Dixon IMC (2019) An Improved Method of Maintaining Primary Murine Cardiac Fibroblasts in TwoDimensional Cell Culture. Sci Rep 9:12889. https://doi.org/10. 1038/s41598-019-49285-9

33. Lei QY, Zhang H, Zhao B, Zha ZY, Bai F, Pei XH, Zhao S, Xiong Y, Guan KL (2008) TAZ promotes cell proliferation and epithelial-mesenchymal transition and is inhibited by the hippo pathway. Mol Cell Biol 28:2426-2436. https://doi.org/10.1128/ MCB.01874-07

34. Liu CY, Zha ZY, Zhou X, Zhang H, Huang W, Zhao D, Li T, Chan SW, Lim CJ, Hong W, Zhao S, Xiong Y, Lei QY, Guan KL (2010) The hippo tumor pathway promotes TAZ degradation by phosphorylating a phosphodegron and recruiting the SCF $\{$ beta $\}$ TrCP E3 ligase. J Biol Chem 285:37159-37169. https://doi.org/ 10.1074/jbc.M110.152942

35. Liu F, Lagares D, Choi KM, Stopfer L, Marinkovic A, Vrbanac V, Probst CK, Hiemer SE, Sisson TH, Horowitz JC, Rosas IO, Fredenburgh LE, Feghali-Bostwick C, Varelas X, Tager AM, Tschumperlin DJ (2015) Mechanosignaling through YAP and TAZ drives fibroblast activation and fibrosis. Am J Physiol Lung Cell Mol Physiol 308:L344-357. https://doi.org/10.1152/ajplung. 00300.2014

36. Maul RS, Song Y, Amann KJ, Gerbin SC, Pollard TD, Chang DD (2003) EPLIN regulates actin dynamics by cross-linking and stabilizing filaments. J Cell Biol 160:399-407. https://doi.org/10. 1083/jcb.200212057

37. Mellacheruvu D, Wright Z, Couzens AL, Lambert JP, St-Denis NA, Li T, Miteva YV, Hauri S, Sardiu ME, Low TY, Halim VA, Bagshaw RD, Hubner NC, Al-Hakim A, Bouchard A, Faubert D, Fermin D, Dunham WH, Goudreault M, Lin ZY, Badillo BG, Pawson T, Durocher D, Coulombe B, Aebersold R, Superti-Furga G, Colinge J, Heck AJ, Choi H, Gstaiger M, Mohammed S, Cristea IM, Bennett KL, Washburn MP, Raught B, Ewing RM, Gingras AC, Nesvizhskii AI (2013) The CRAPome: a contaminant repository for affinity purification-mass spectrometry data. Nat Methods 10:730-736. https://doi.org/10.1038/nmeth.2557

38. Miranda MZ, Bialik JF, Speight P, Dan Q, Yeung T, Szaszi K, Pedersen SF, Kapus A (2017) TGF-beta1 regulates the expression and transcriptional activity of TAZ protein via a Smad3-independent, myocardin-related transcription factor-mediated mechanism. J Biol Chem 292:14902-14920. https://doi.org/10.1074/jbc.M117. 780502

39. Noguchi S, Saito A, Mikami Y, Urushiyama H, Horie M, Matsuzaki H, Takeshima H, Makita K, Miyashita N, Mitani A, Jo T, Yamauchi Y, Terasaki Y, Nagase T (2017) TAZ contributes to pulmonary fibrosis by activating profibrotic functions of lung fibroblasts. Sci Rep 7:42595. https://doi.org/10.1038/srep42595

40. Rashidian J, Le Scolan E, Ji X, Zhu Q, Mulvihill MM, Nomura D, Luo K (2015) Ski regulates Hippo and TAZ signaling to suppress breast cancer progression. Sci Signal 8: ra14 doi: https://doi.org/ 10.1126/scisignal.2005735.

41. Santiago JJ, McNaughton LJ, Koleini N, Ma X, Bestvater B, Nickel BE, Fandrich RR, Wigle JT, Freed DH, Arora RC, Kardami E (2014) High molecular weight fibroblast growth factor-2 in the human heart is a potential target for prevention of cardiac remodeling. PLoS ONE 9:e97281. https://doi.org/10.1371/journ al.pone.0097281

42. Schepers D, Doyle AJ, Oswald G, Sparks E, Myers L, Willems PJ, Mansour S, Simpson MA, Frysira H, Maat-Kievit A, Van
Minkelen R, Hoogeboom JM, Mortier GR, Titheradge H, Brueton L, Starr L, Stark Z, Ockeloen C, Lourenco CM, Blair E, Hobson E, Hurst J, Maystadt I, Destree A, Girisha KM, Miller M, Dietz HC, Loeys B, Van Laer L (2015) The SMAD-binding domain of SKI: a hotspot for de novo mutations causing Shprintzen-Goldberg syndrome. Eur J Hum Genet 23:224-228. https://doi.org/10. 1038/ejhg.2014.61

43. Schiller HB, Friedel CC, Boulegue C, Fassler R (2011) Quantitative proteomics of the integrin adhesome show a myosin II-dependent recruitment of LIM domain proteins. EMBO Rep 12:259-266. https://doi.org/10.1038/embor.2011.5

44. Schneider CA, Rasband WS, Eliceiri KW (2012) NIH Image to ImageJ: 25 years of image analysis. Nat Methods 9:671-675. https://doi.org/10.1038/nmeth.2089

45. Serini G, Bochaton-Piallat ML, Ropraz P, Geinoz A, Borsi L, Zardi L, Gabbiani G (1998) The fibronectin domain ED-A is crucial for myofibroblastic phenotype induction by transforming growth factor-beta1. J Cell Biol 142:873-881. https://doi.org/ $10.1083 /$ jcb.142.3.873

46. Shimazaki M, Nakamura K, Kii I, Kashima T, Amizuka N, Li M, Saito M, Fukuda K, Nishiyama T, Kitajima S, Saga Y, Fukayama M, Sata M, Kudo A (2008) Periostin is essential for cardiac healing after acute myocardial infarction. J Exp Med 205:295-303. https://doi.org/10.1084/jem.20071297

47. Shimomura T, Miyamura N, Hata S, Miura R, Hirayama J, Nishina H (2014) The PDZ-binding motif of Yes-associated protein is required for its co-activation of TEAD-mediated CTGF transcription and oncogenic cell transforming activity. Biochem Biophys Res Commun 443:917-923. https://doi.org/ 10.1016/j.bbrc.2013.12.100

48. Shinagawa T, Nomura T, Colmenares C, Ohira M, Nakagawara A, Ishii S (2001) Increased susceptibility to tumorigenesis of ski-deficient heterozygous mice. Oncogene 20:8100-8108. https://doi.org/10.1038/sj.onc.1204987

49. Szeto SG, Narimatsu M, Lu M, He X, Sidiqi AM, Tolosa MF, Chan L, De Freitas K, Bialik JF, Majumder S, Boo S, Hinz B, Dan Q, Advani A, John R, Wrana JL, Kapus A, Yuen DA (2016) YAP/TAZ Are Mechanoregulators of TGF-beta-Smad Signaling and Renal Fibrogenesis. J Am Soc Nephrol 27:3117-3128. https://doi.org/10.1681/ASN.2015050499

50. Talele NP, Fradette J, Davies JE, Kapus A, Hinz B (2015) Expression of alpha-Smooth Muscle Actin Determines the Fate of Mesenchymal Stromal Cells. Stem cell reports 4:1016-1030. https://doi.org/10.1016/j.stemcr.2015.05.004

51. Tallquist MD, Molkentin JD (2017) Redefining the identity of cardiac fibroblasts. Nat Rev Cardiol 14:484-491. https://doi.org/ 10.1038/nrcardio. 2017.57

52. Tecalco-Cruz AC, Rios-Lopez DG, Vazquez-Victorio G, Rosales-Alvarez RE, Macias-Silva M (2018) Transcriptional cofactors Ski and SnoN are major regulators of the TGF-beta/ Smad signaling pathway in health and disease. Signal Transduct Target Ther 3:15. https://doi.org/10.1038/s41392-018-0015-8

53. Teo G, Liu G, Zhang J, Nesvizhskii AI, Gingras AC, Choi H (2014) SAINTexpress: improvements and additional features in Significance Analysis of INTeractome software. J Proteomics 100:37-43. https://doi.org/10.1016/j.jprot.2013.10.023

54. Ueki N, Hayman MJ (2003) Signal-dependent N-CoR requirement for repression by the Ski oncoprotein. J Biol Chem 278:24858-24864. https://doi.org/10.1074/jbc.M303447200

55. von Gise A, Lin Z, Schlegelmilch K, Honor LB, Pan GM, Buck JN, Ma Q, Ishiwata T, Zhou B, Camargo FD, Pu WT (2012) YAP1, the nuclear target of Hippo signaling, stimulates heart growth through cardiomyocyte proliferation but not hypertrophy. Proc Natl Acad Sci USA 109:2394-2399. https://doi.org/ 10.1073/pnas.1116136109 
56. Xiao Y, Hill MC, Li L, Deshmukh V, Martin TJ, Wang J, Martin JF (2019) Hippo pathway deletion in adult resting cardiac fibroblasts initiates a cell state transition with spontaneous and self-sustaining fibrosis. Genes Dev 33:1491-1505. https://doi. org/10.1101/gad.329763.119

57. Xiao Y, Hill MC, Zhang M, Martin TJ, Morikawa Y, Wang S, Moise AR, Wythe JD, Martin JF (2018) Hippo signaling plays an essential role in cell state transitions during cardiac fibroblast development. Dev Cell 45(153-169):e156. https://doi.org/10. 1016/j.devcel.2018.03.019

58. Xie M, Wu X, Zhang J, Zhang J, Li X (2017) Ski regulates Smads and TAZ signaling to suppress lung cancer progression. Mol Carcinog 56:2178-2189. https://doi.org/10.1002/mc.22661

59. $\mathrm{Xu} \mathrm{W}$, Angelis K, Danielpour D, Haddad MM, Bischof O, Campisi J, Stavnezer E, Medrano EE (2000) Ski acts as a corepressor with $\mathrm{Smad} 2$ and $\mathrm{Smad} 3$ to regulate the response to type beta transforming growth factor. Proc Natl Acad Sci USA 97:5924-5929. https://doi.org/10.1073/pnas.090097797

60. Zeglinski MR, Davies JJ, Ghavami S, Rattan SG, Halayko AJ, Dixon IM (2016) Chronic expression of Ski induces apoptosis and represses autophagy in cardiac myofibroblasts. Biochim Biophys
Acta 1863:1261-1268. https://doi.org/10.1016/j.bbamcr.2016.03. 027

61. Zeglinski MR, Roche P, Hnatowich M, Jassal DS, Wigle JT, Czubryt MP, Dixon IM (2016) TGFbeta1 regulates Scleraxis expression in primary cardiac myofibroblasts by a Smad-independent mechanism. Am J Physiol Heart Circ Physiol 310:H239-249. https://doi.org/10.1152/ajpheart.00584.2015

62. Zhang H, Liu CY, Zha ZY, Zhao B, Yao J, Zhao S, Xiong Y, Lei QY, Guan KL (2009) TEAD transcription factors mediate the function of TAZ in cell growth and epithelial-mesenchymal transition. J Biol Chem 284:13355-13362. https://doi.org/10.1074/jbc. M900843200

63. Zhang N, Bai H, David KK, Dong J, Zheng Y, Cai J, Giovannini M, Liu P, Anders RA, Pan D (2010) The Merlin/NF2 tumor suppressor functions through the YAP oncoprotein to regulate tissue homeostasis in mammals. Dev Cell 19:27-38. https://doi.org/10. 1016/j.devcel.2010.06.015

64. Zheng L, Baumann U, Reymond JL (2004) An efficient one-step site-directed and site-saturation mutagenesis protocol. Nucleic Acids Res 32:e115. https://doi.org/10.1093/nar/gnh110 